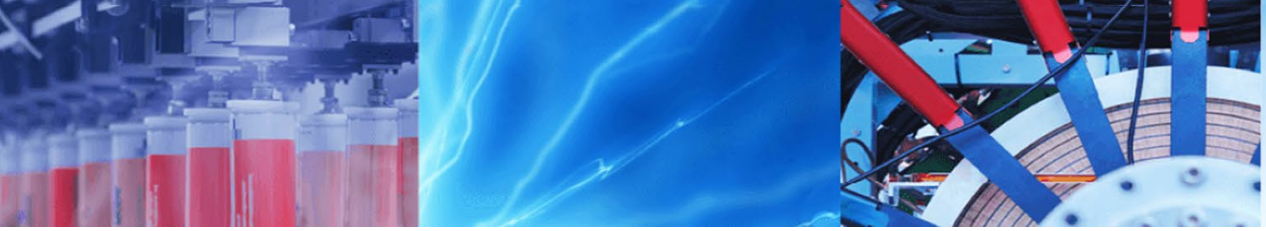

Research Article

\title{
Solar photovoltaic-based microgrid hosting capacity evaluation in electrical energy distribution network with voltage quality analysis
}

\author{
Arvind Sharma ${ }^{1}\left[\right.$ Mohan Kolhe ${ }^{1} \cdot$ Alkistis Kontou $^{2} \cdot$ Dimitrios Lagos $^{2} \cdot$ Panos Kotsampopoulos $^{2}$
}

Received: 10 January 2021 / Accepted: 30 March 2021

Published online: 20 April 2021

(c) The Author(s) 2021 OPEN

\begin{abstract}
In this paper, solar photovoltaic hosting capacity within the electrical distribution network is estimated for different buses, and the impacts of high PV penetration are evaluated using power hardware-in-loop testing methods. It is observed that the considered operational constraints (i.e. voltage and loadings) and their operational limits have a significant impact on the hosting capacity results. However, with increasing photovoltaic penetration, some of the network buses reach maximum hosting capacity, which affects the network operation (e.g. bus voltages, line loading). The results show that even distributing the maximum hosting capacity among different buses can increase the bus voltage rise to $9 \%$. To maintain the network bus voltages within acceptable limits, reactive power voltage-based droop control is implemented in the photovoltaic conditioning devices to test the dynamics of the network operation. The results show that implementation of the droop control technique can reduce the maximum voltage rise from $9 \%$ to $4 \%$ in the considered case. This paper also presents the impact of forming a mesh type network (i.e. from radial network) on the voltage profile during PV penetration, and a comparative analysis of the operational performance of a mesh type and radial type electrical network is performed. It is observed that the cumulative effect of forming a mesh type network along with a droop control strategy can further improve the voltage profile and contribute to increase photovoltaic penetration. The results are verified using an experimental setup of digital real-time simulator and power hardware-in-loop test methods. The results from this work will be useful for estimating the appropriate photovoltaic hosting capacity within a distribution network and implementation of a droop control strategy in power conditioning devices to maintain the network operational parameters within the specified limits.
\end{abstract}

\section{Highlights}

- Voltage and line loading constraints' combination can reduce PV hosting capacity by $50 \%$ as compared to only voltage as a constraint.
- Implementation of reactive power versus voltage droop control in PV power conditioning device can reduce voltage variation from $9 \%$ to $4 \%$.

- In a PV integrated electrical energy network, line loading can be reduced by $20 \%$ if the network is configured from radial to mesh type.

Keywords Solar photovoltaic · Microgrid · Sustainable electrical distribution network · PV hosting capacity · Voltagereactive power droop technique

\footnotetext{
$\triangle$ Arvind Sharma, arvind.sharma@uia.no; Mohan Kolhe, mohan.l.kolhe@uia.no; Alkistis Kontou, alkistiskont@mail.ntua.gr; Dimitrios Lagos, dimitrioslagos@mail.ntua.gr; Panos Kotsampopoulos, kotsa@power.ece.ntua.gr|'Department of Engineering and Sciences, University of Agder, Grimstad, Norway. ${ }^{2}$ National Technical University of Athens, Athens, Greece.
} 


\section{Introduction}

The market for photovoltaic (PV) power systems is increasing exponentially, at a rate of $47 \%$ per year, due to capital cost reduction and technological advancements [1]. Most of the PV generation units are distributed in nature and connected within low- or medium-voltage distribution networks. However, with the limitations of the electrical energy distribution network, appropriate PV capacity can be connected to different buses to maintain the operational parameters within the acceptable limits without the need for any significant modifications to the existing distribution network [2]. The PV capacity at the nodes of the electrical distribution network will affect the operational parameters (e.g. node voltages, line loadings, reverse current flow, short circuit current).

The PV hosting capacity $(\mathrm{HC})$ can be analyzed in two categories: (i) based on network performance and load characteristics, and (ii) based on network operational parameters for future planning and expansion of the electrical network. The network operational parameters (e.g. bus overvoltage, line overloading, power quality) need to be critically evaluated to estimate the PV HC at different nodes of the distribution network. In Navarro and Navarro [2], the PV hosting capacity within an electrical distribution network was analyzed at different buses considering only the rated PV capacity, but PV output and simultaneous load profile at a particular node was not considered. An approach for enhancing PV HC based on a reactive power control strategy was presented by Atmaja et al. [3], but it did not include load flow analysis with simultaneous penetration of PV capacity at different nodes. A probabilistic approach-based method for PV HC was presented by Niederhuemer and Schwalbe [4] considering the worst-case scenario (i.e. maximum PV and low load), but network operational parameters were not analyzed. The placement of distributed generation within the network was evaluated through power quality (harmonic distortion) by Saber et al. [5], but the HC of individual buses with loading impact was not analyzed. The PV HC within an electrical distribution network was evaluated by Al-Saffar et al. [6] using a Monte Carlo probabilistic technique with random PV placements, but it did not provide analysis on individual buses. To determine the suitable capacity and position for a grid-autonomous PV system for rural areas, a GIS module was used by Zhang et al. [7] that considered social, economic, technical and environmental aspects. The authors focused mainly on rural electrification, but integration with the electrical grid was also covered. An optimization-discrete tabu search was presented for sizing stand-alone solar-wind-battery-based hybrid systems. The reliability of the stand-alone system was validated with applied algorithms and effectiveness, but the suitability of the design system was not tested with the grid [8]. Most of the reviewed literatures [3-8] have not covered a comparative assessment of hosting capacity considering various operational constraints. Therefore, it is essential to analyze PV HC within the distribution network at different nodes with simultaneous PV and load profiles.

The operational parameters can be managed within the prescribed limits through appropriate embedded control strategies in the PV power conditioning devices. Katiraei et al. [9] reported a phasor measurement analysis for a PV system, but potential mitigation techniques were not elaborated. A PV penetration study was conducted by the Department of Energy's SunShot Program [10] and reported that the voltage at the PV plant had surpassed maximum PV generation; in addition, a mitigation technique was presented.

Another PV impact study for an urban low-voltage network in Sri Lanka was presented by Chathurangi et al. [11], which suggested that the maximum rise in feeder voltage was observed in the daytime when energy demand was low and maximum solar radiation was available, but mitigation techniques were not adequately tested in real-time conditions using digital real-time simulator (DRTS) and power hardware-in-loop (PHIL) methods. Wong et al. [12] discussed the major impacts of $\mathrm{PV}$ integration for power quality issues, protection relays, etc., but daily load and generation profiles were not considered. An optimal centralized coordinated voltage control algorithm in a PV inverter was tested and validated using a PHIL configuration method for a low-voltage distribution network [13]. The operational performance of standard droop control techniques of PV inverters was investigated during the transition to islanded operation from grid-connected mode [14], and the results showed that PHIL simulation of local control on the benchmark system validated the appropriateness of the proposed real-time simulation approach. To address voltage quality problems, some countries have implemented technical solutions at the device level (i.e. PV inverters). For example, in Germany, to overcome overvoltage events, beginning in January 2012, a fixed limitation of the active power (i.e. $70 \%$ of the nominal peak output power of the PV system) feed-in by each PV system became mandatory [15]. Similarly, other alternative solutions to curtailment of active power by domestic load shifting and use of energy storage have been discussed [16]. To improve the power factor of three-phase PV inverters, a reactive power control technique was proposed $[17,18]$. Different techniques including active power curtailment, reactive power compensation and 
energy storage have been presented to address voltage quality challenges due to high PV penetration [19].

However, PV penetration has also been increasing through PV-based microgrids, and this has not been sufficiently addressed in the reviewed literatures [20-22]. Based on the above-mentioned issues and challenges, the key research objectives in the present work are formulated as follows: (i) first, to estimate the HC of PV at the distribution network buses with voltage and power line loadings as constraints, by anticipating solar generation and load profiles at the nodes; (ii) second, to analyze and verify the impact of increasing PV penetration on selected distribution network buses through DRTS and PHIL methods, and finally, (iii) to test a reactive power versus voltage droop control technique (a possible mitigation technique) in $\mathrm{PV}$ power conditioning devices.

This work uses a unique approach involving simultaneous PV and load profile analysis to maintain voltage and power line loadings within the prescribed limits. Th paper is organized as follows: In Sect. 2, the system description and network operation analysis without PV are presented. Section 3 provides PV HC analysis. In Sect. 4, the testing setup for DRTS and PHIL is described. A reactive power versus voltage (i.e. QV) droop control technique is used in PV inverter(s) to test the dynamics in real-time conditions, and is presented in Sect. 5. In Sect. 6, a mesh network is used, and the cumulative impact of the droop control technique in a mesh network is studied. The conclusion is provided in Sect. 7.

\section{PV distribution network without PV integration (Case A)}

\subsection{System description}

In this work, a typical medium-voltage (MV) distribution network (i.e. CIGRE electrical network) [23] is used as a case, and its schematic is shown in Fig. 1. The CIGRE network is widely used as a benchmark in electrical energy system analysis. The technical details of transformers, cable line length, voltage and current ratings, resistance, inductance, load types and power factor are taken from ref [23]. The distribution network consists of two feeders (i.e. 1 and 2), and they are linked separately to transformers (i.e. $T_{1}$ and $T_{2}$, each with rated capacity of $25 \mathrm{MVA}$ at $110 \mathrm{kV} / 20 \mathrm{kV}$ ). The network consists of 14 buses (i.e. $B_{1}$ to $\left.B_{14}\right)$, in which buses $B_{1}$ to $B_{11}$ are connected to feeder 1 , and buses $B_{12}$ to $B_{14}$ to feeder 2. To compare and analyze the results of the distribution network, all 14 buses are categorized into three groups, A, B and C. Group A represents buses $B_{1}$ to $B_{6}$, Group $B$ buses $B_{7}$ to $B_{11}$, and Group $C$ buses $B_{12}$ to $B_{14}$.

There are a total of 12 lines (i.e. $L_{1-2}, L_{2-3}, L_{3-4}, L_{4-5}, L_{5-6}$, $L_{7-8}, L_{8-9}, L_{9-10}, L_{10-11}, L_{3-8}, L_{12-13}$ and $\left.L_{13-14}\right)$, and these lines are also categorized in Groups A, B and C: lines $L_{1-2}, L_{2-3}$, $L_{3-4}, L_{4-5}$ and $L_{5-6}$ are in Group $A$, lines $L_{7-8}, L_{8-9}, L_{9-10}, L_{10-11}$ and $L_{3-8}$ are in Group $B$, and lines $L_{12-13}$ and $L_{13-14}$ are in Group $C$. There are three switches $\left(S_{1}, S_{2}\right.$ and $\left.S_{3}\right)$ which can be used to create a mesh type electrical network.

A typical daily load profile is used to evaluate the performance of the distribution network, and it is illustrated in Fig. 2. The daily load profile for all the buses is considered the same. However, maximum load demands are varied for different buses, and values of the maximum load were taken from ref [23]. The apparent power for the buses is as follows: $B_{1}-:$ 12.71MVA $(12.44+\mathrm{j} 2.53), B_{2}-:(0), B_{3}-: 0.30$ MVA $(0.27+\mathrm{j} 0.12), B_{4}-: 0.22 \mathrm{MVA}(0.22+\mathrm{j} 0.05), B_{5}-: 0.37$ MVA $(0.36+\mathrm{j} 0.09), B_{6}-: 0.28 \mathrm{MVA}(0.27+\mathrm{j} 0.07), B_{7}-: 0.08$ MVA $(0.07+\mathrm{j} 0.04), B_{8}-: 0.48 \mathrm{MVA}(0.47+\mathrm{j} 0.12), B_{9}-: 0.61$ MVA $(0.59+\mathrm{j} 0.15), B_{10}-: 0.46 \mathrm{MVA}(0.44+\mathrm{j} 0.13), B_{11}: 0.27$ MVA $(0.26+\mathrm{j} 0.07), B_{12}-: 11.99$ MVA $(3.17+\mathrm{j} 11.56), B_{13}-:$ $0.04 \mathrm{MVA}(0.03+\mathrm{j} 0.02)$ and $B_{14}: 6.71 \mathrm{MVA}(6.48+\mathrm{j} 1.73)$.

In the selected distribution network, the nominal bus voltage (i.e. $20 \mathrm{kV}$ line to line (1 p.u.)), maximum active load (12.44 MW) and maximum reactive load (2.53 MVAr) are considered as 1 p.u. (12.70 MVA). The load profile is considered to cover two scenarios; the first includes minimum load and maximum PV generation, and the second includes maximum load and minimum PV generation. It is observed from a typical daily load profile that the minimum load demand of 0.10 p.u. emerges during nighttime (00:00 to 01:00); however, the maximum load demand of 0.90 p.u. is observed in the morning (08:00 to 09:00) as well as in the evening (from 19:00 to 20:00).

\subsection{Results and discussion for Case A}

Case $\mathrm{A}$ represents the scenario when $\mathrm{PV}$ is not integrated into the distribution network, and the switches $S_{1}, S_{2}$ and $S_{3}$ are in the open conditions. In Group A, the voltage of the six buses $\left(V_{1}\right.$ to $\left.V_{6}\right)$ and \% loading (of the rated capacity of the power line) on the five lines $\left(L_{1-2}, L_{2-3}, L_{3-4}, L_{4-5}\right.$ and $\left.L_{5-6}\right)$ are shown in Figs. 3 and 4, respectively. In the considered distribution network, bus $B_{1}$ represents the slack bus, and its voltage is stable as compared to all other buses within the network. It is observed from Fig. 3 that the bus voltage of all six buses $\left(V_{1}\right.$ to $\left.V_{6}\right)$ never falls below 0.98 p.u., but the maximum voltage of buses reaches 1 p.u. The lowest voltage appears during peak demand hours (08:00 to 09:00 and 19:00 to 21:00). It is observed that the bus voltages do not violate the defined voltage regulation criteria (i.e. $0.90 \leq V_{i} \leq 1.10$ ). 


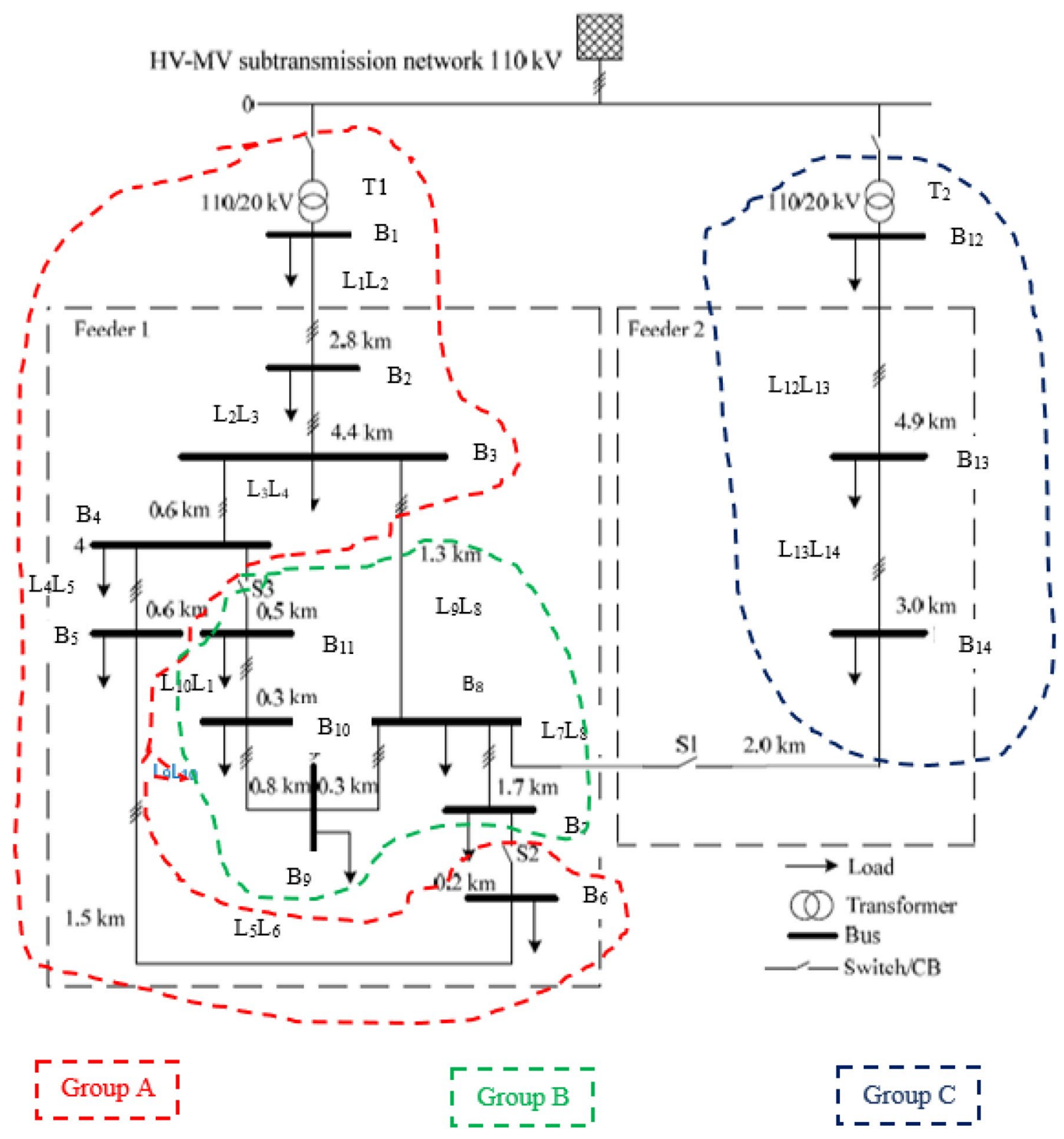

Fig. 1 Line diagram of MV CIGRE electrical network

Fig. 2 A typical load profile

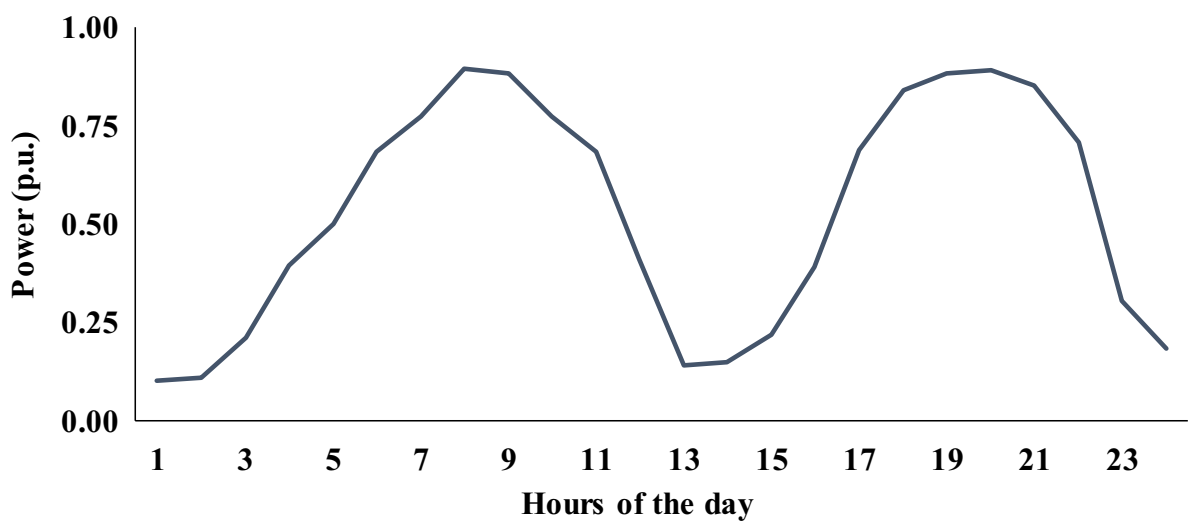


In Group A, the maximum line loading is $9 \%$ for the lines $L_{1-2}$ and $L_{2-3}$, whereas the loading of the remaining lines (e.g. $L_{3-4} L_{4-5}$ and $L_{5-6}$ ) is below $4 \%$ throughout the day. The line loading graph clearly follows the same characteristics as the load demand curve shown in Fig. 2.

In Group B, the voltages of the five buses $\left(V_{7}\right.$ to $\left.V_{11}\right)$ and loading of the five lines $\left(L_{7-8}, L_{8-9}, L_{9-10}, L_{10-11}\right.$ and $\left.L_{3-8}\right)$ are shown in Figs. 5 and 6 , respectively. It is observed that the bus voltage of the buses $\left(V_{7}\right.$ to $\left.V_{11}\right)$ never falls below 0.97 p.u. The lowest bus voltages appear during the peak demand hours (08:00 to 09:00 and 19:00 to
21:00), and the maximum voltage is 1 p.u. None of the buses violates the defined voltage regulation criteria (i.e. $0.90 \leq V_{i} \leq 1.10$ ).

In Group B, the maximum line loading is $4 \%$ and $5 \%$ for lines $L_{8-9}$ and $L_{3-8}$, respectively, whereas loadings of the remaining lines (e.g. $L_{7-8}, L_{9-10}$ and $L_{10-11}$ ) remain below $3 \%$ throughout the day. The loading of line $L_{3-8}$ is affected by the load connected at buses 7, 8, 9, 10 and 11, and the loading of line $L_{3-8}$ is higher than that of the other line loadings. It is observed from Fig. 6 that the line loadings are below the defined limit (100\%).
Fig. 3 Variation in bus voltages of Group A in Case A

Fig. 4 Variation in line loading of Group A in Case A

Fig. 5 Variation in bus voltages of Group B in Case A
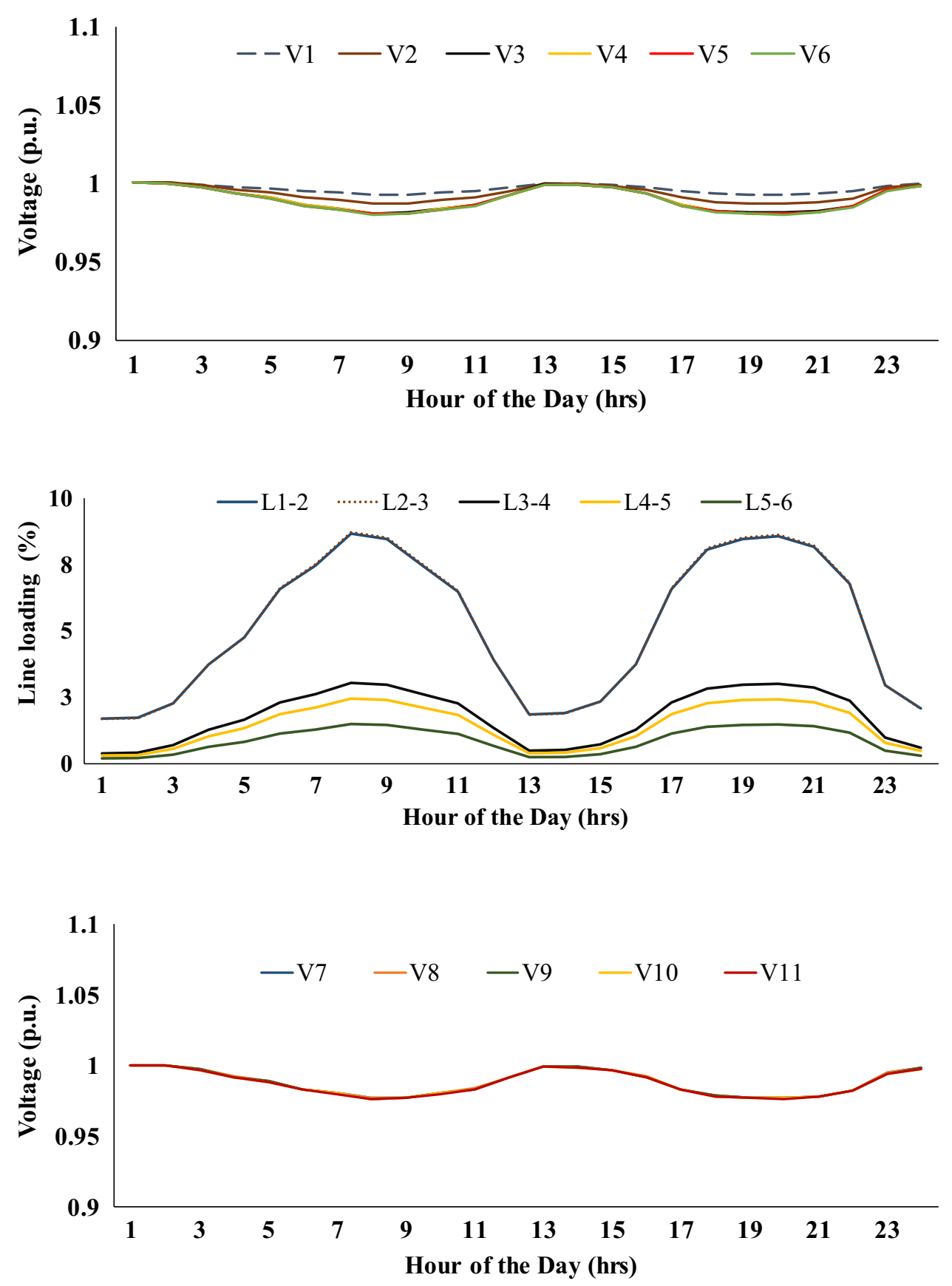

SN Applied Sciences 

of Group B in Case A
Fig. 6 Variation in line loadings
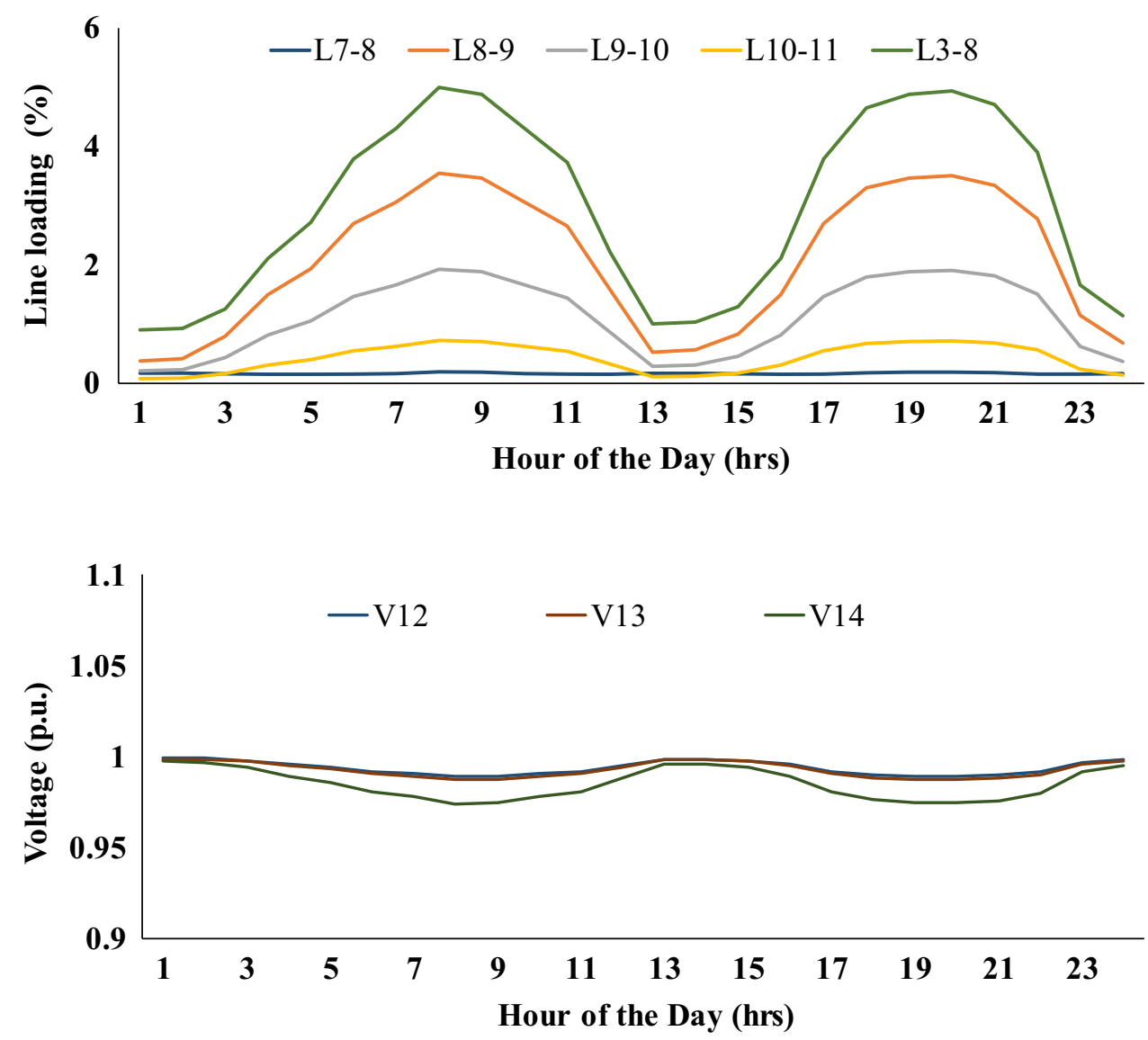

Fig. 7 Variation in bus voltages of Group C in Case A

Fig. 8 Variation in line loadings of Group C in Case A

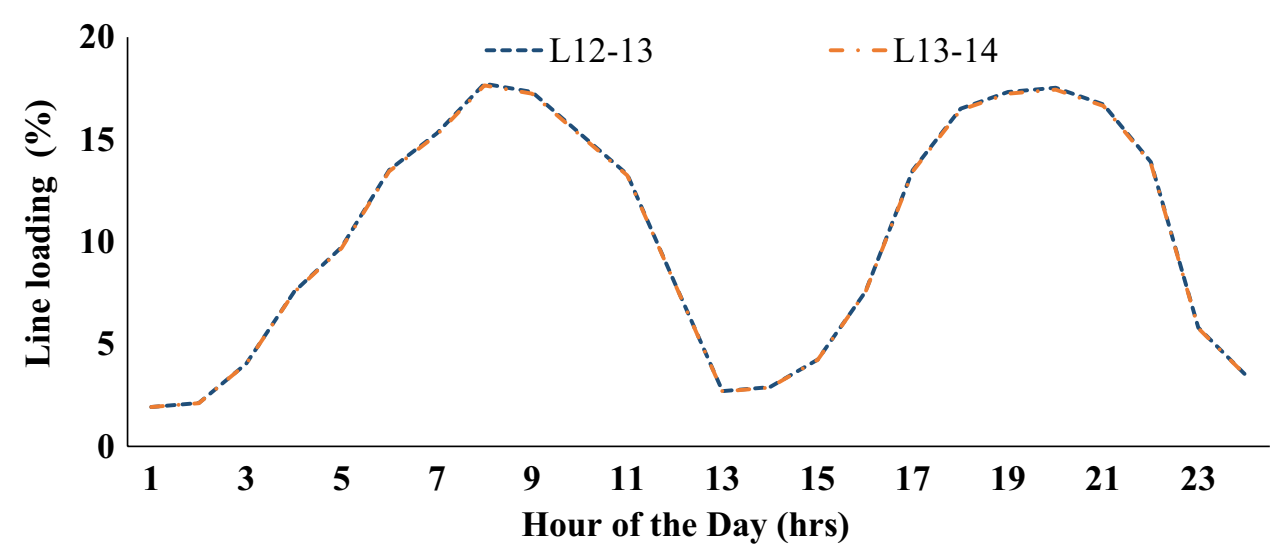

In Group C, the voltage of three buses $\left(V_{12}, V_{13}\right.$ and $\left.V_{14}\right)$ and loading of two lines $\left(L_{12-13}\right.$ and $\left.L_{13-14}\right)$ are shown in Figs. 7 and 8 . It is observed from Fig. 7 that the bus $V_{12}$ represents the slack bus of feeder 2 , and its bus voltage is quite stable (i.e. $0.98<V_{12}<1.0$ ). However, voltages at buses $V_{13}$ and $V_{14}$ vary between 0.97 and 0.99 p.u. The lowest voltage of 0.97 p.u. is recorded for bus $V_{14}$ during the peak demand hours (08:00 to 09:00 and 19:00 to 21:00).

In Group C, the maximum line loading is $18 \%$ for lines $L_{12-13}$ and $L_{13-14}$. The loads connected at feeders 1 and 2 are the same. However, in the case of feeder 1 , the total load is placed at 11 buses $\left(B_{1}\right.$ to $\left.B_{11}\right)$, and in the case of feeder 2 , the load is connected at three buses $\left(B_{12}, B_{13}\right.$ and $\left.B_{14}\right) ;$ therefore, the maximum line loading of feeder 2 is twice $(18 \%)$ that of feeder $1(9 \%)$.

The variation in transformer loadings (i.e. $T_{1}$ and $T_{2}$ ) for a typical day is shown in Fig. 9. The maximum loadings of transformer $T_{1}$ and $T_{2}$ (i.e. power loading) are $29 \%$ and $34 \%$, respectively; however, the minimum loading for both transformers is between $3 \%$ and $4 \%$ during nighttime (00:00 to $01: 00)$. The average daily energy loading of transformers $T_{1}$ and $T_{2}$ is $17 \%$ and $20 \%$, respectively. 
Fig. 9 Variation in transformer loading for a typical day in Case A

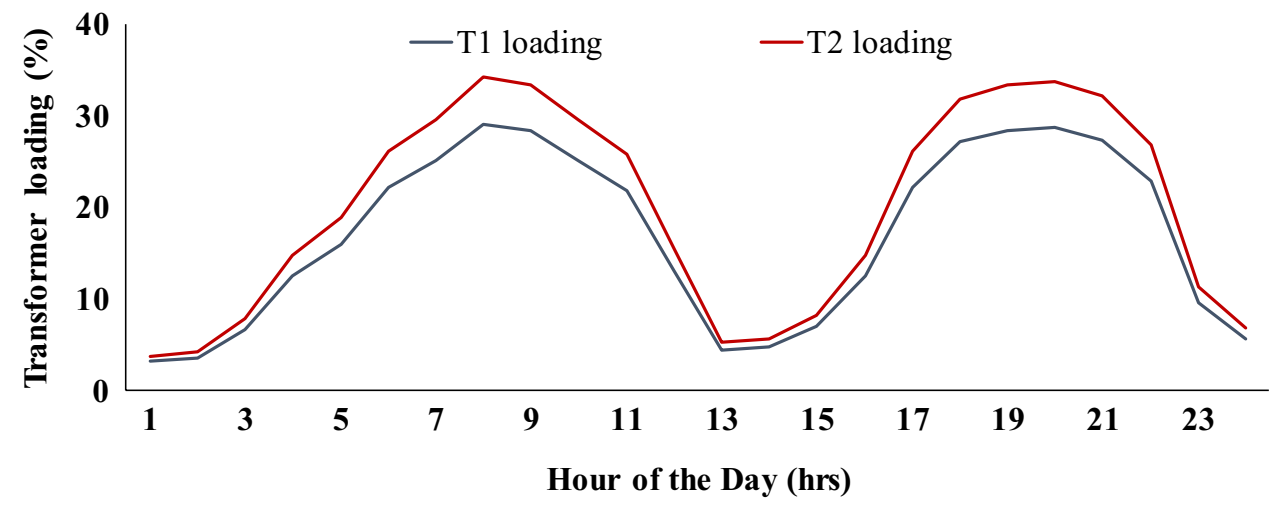

The results of Case $A$ show that the distribution network does not violate any voltage or overload conditions for the considered load profile. This indicates that the distribution network has the capacity to integrate a solar PV-based microgrid, but how much PV can be connected to the distribution network depends on the $\mathrm{HC}$ of the network.

In this paper, the $\mathrm{HC}$ of the distribution network is evaluated using the DIgSILENT PowerFactory [24], and the impacts of the PV integration within the distribution network are then analyzed using the DRTS and PHIL simulation methods. The $\mathrm{HC}$ at the individual bus of the distribution network is estimated so that appropriate PV capacity can be connected to the distribution network without violating the network operational constraints.

\section{Analysis of PV hosting capacity in the electrical distribution network}

In this work, PV HC is estimated for two scenarios. In the first scenario $\left(\mathrm{HC}_{1}\right)$, only the voltage parameter is considered as a constraint, whereas in the second scenario $\left(\mathrm{HC}_{2}\right)$, voltage and loading (i.e. line and transformer loading) are both taken as constraints. The methodology for estimating the hosting capacity is given in the following section.

\subsection{Methodology for estimating PV hosting capacity}

This work investigates PV HC at different buses of a distribution network considering a typical daily load profile as well as a PV generation profile. The constraints and objective function are described in Eqs. (1) to (7), for estimating the maximum $\mathrm{HC}$ at any of the 14 buses within the distribution network. The main considered variables are PV capacities, voltage at bus terminals, line current, active and reactive line power flow, and active and reactive power exchange with the upstream grid. As the HC depends on the load, various peak load demands are considered at different buses within the distribution network. An optimization technique is used to calculate the maximum $\mathrm{HC}$ [24]. In an $n$ bus network system, the maximum hosting capacity of a bus within the network is given by Eq. (1).

$P V_{\max }\left(X_{\mathrm{n}}\right)=\operatorname{Max} P V\left(X_{n}, t\right)$

$0.90 \leq V_{\mathrm{n}}(\mathrm{t}) \leq 1.10$

$0 \leq T_{1}(t) \leq 0.80$

$0 \leq T_{2}(t) \leq 0.80$

$I_{\mathrm{jk}}^{\min } \leq I_{\mathrm{jk}}(\mathrm{t}) \leq I_{\mathrm{jk}}^{\max }$

$P_{\mathrm{n}}^{\mathrm{L}, \min } \leq P_{\mathrm{n}}^{\mathrm{L}}(\mathrm{t}) \leq P_{\mathrm{n}}^{\mathrm{L}, \max }$

$Q_{n}^{L, m i n} \leq Q_{n}^{L}(t) \leq Q_{n}^{L, \max }$,

where

$\mathrm{DG}_{\mathrm{Max}}\left(\mathrm{X}_{n}, t\right)=$ maximum hosting capacity of bus $n$ at time $t$;

$V_{\mathrm{n}}(t)=$ voltage of bus terminal $n$ at time $t$;

$I_{\mathrm{jk}}(t)=$ loading of line $\mathrm{jk}$ at time $t$;

$T_{1}(t) \& T_{2}(t)=$ transformer loadings at time $t$;

$P_{n}^{\mathrm{L}}(t)=$ active load connected to bus $n$ at time $t$;

$Q_{n}^{L}(t)=$ reactive load connected to bus $n$ at time $t$.

A flowchart of the proposed methodology for estimating the $\mathrm{HC}$ at a bus within the network is shown in Fig. 10. To estimate the hosting capacity for a bus within the network, the initial conditions are set including maximum load connected to the different buses, load profile, voltage limits, current carrying capacity of lines and transformer loadings. Initially, minimum PV capacity (i.e. $1 \%$ of transformer capacity) is allocated at a bus $n$, and it is increased in steps until it violates the defined conditions as given in Eqs. (2-7). In this paper, the network behavior is analyzed for the entire day ( $24 \mathrm{~h}$ ) and mainly covers two circumstances: (i) voltage rise problems due to low load demand 


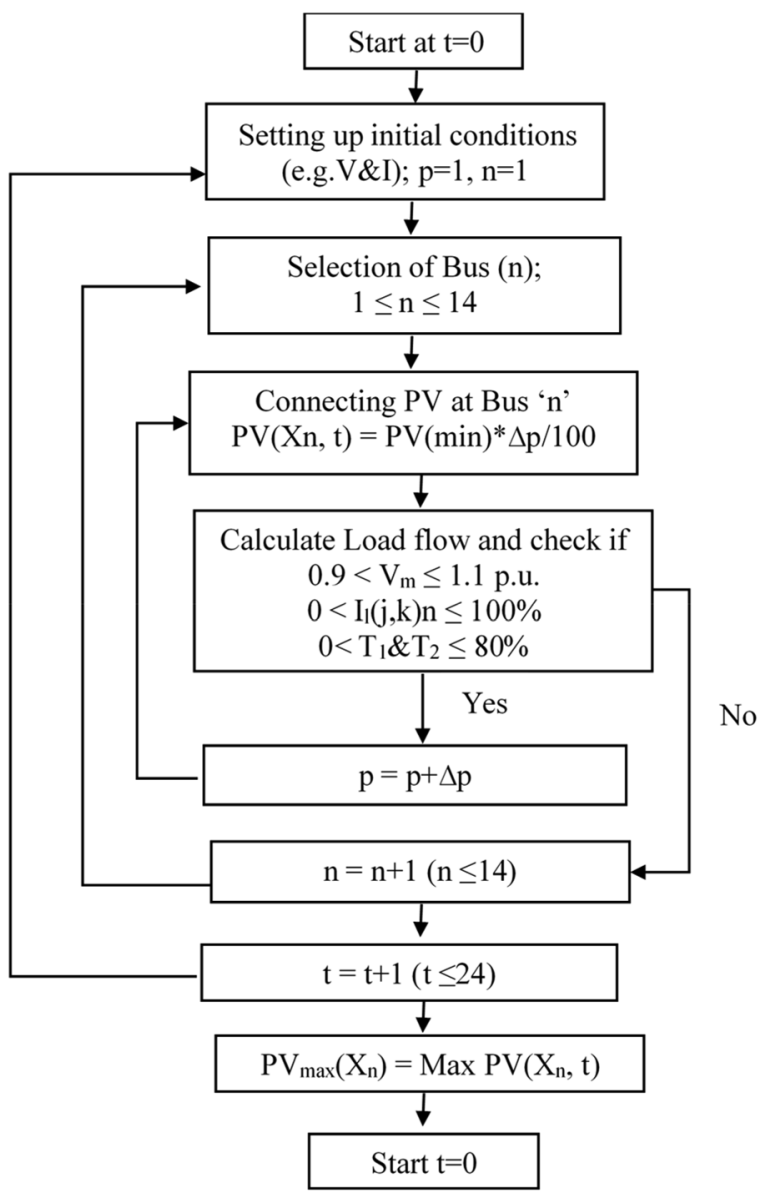

Fig. 10 Flow diagram for estimating the $\mathrm{HC}$ of the network and high PV generation, and (ii) loading problems due to high demand and high generation. The proposed methodology estimates the $\mathrm{HC}$ of an individual bus for a considered load profile, as illustrated in Fig. 10.

\subsection{PV hosting capacity estimation}

In this work, PV HC is estimated for two different scenarios. In the first scenario $\left(\mathrm{HC}_{1}\right)$, only the voltage parameter is considered a constraint; however, in the second scenario $\left(\mathrm{HC}_{2}\right)$, voltage and loading of lines are both taken as constraints. In Table 1 , the hosting capacities $\left(\mathrm{HC}_{1}\right.$ and $\left.\mathrm{HC}_{2}\right)$ of the individual bus with the most impacted line and bus are given. The parameter'most impacted bus/line due to voltage or loading constraints' reveals that the $\mathrm{HC}$ of a bus is limited by that component within the distribution network. In the case of $\mathrm{HC}_{1}$, bus voltage is the limiting component for all 14 buses, as only the 'voltage' parameter is a constraint in this scenario. It is observed that $B_{10}$ is the most impacted bus for estimating the $\mathrm{HC}$ of $B_{1}$ and $B_{10}$; however, $B_{14}$ is the most impacted bus when PV HC is estimated for bus $B_{12}$ and $B_{14}$. In other words, increasing the $\mathrm{PV}$ at buses $B_{1}$ and $B_{10}$ strongly influences the voltage of bus $B_{10}$, and similarly, increasing the PV at buses $B_{12}$ and $B_{14}$ shows maximum impact on the voltage of bus $B_{14}$. The values of PV HC are examined for both cases and shown in Table 1.

$\mathrm{HC}_{1}$ and $\mathrm{HC}_{2}$ are illustrated in Fig. 11. In feeder $1, \mathrm{HC}_{2}$ of buses $B_{1}$ and $B_{2}$ decreases by $60 \%$ and $57 \%$, respectively, as compared to $\mathrm{HC}_{1}$; however, there is no change in the hosting capacities of the remaining buses. It can be seen that in

Table 1 Hosting capacity of each bus in a distribution network

\begin{tabular}{|c|c|c|c|c|c|}
\hline \multirow[t]{2}{*}{ Bus no. } & \multicolumn{2}{|c|}{ With only voltage constraint } & \multicolumn{2}{|c|}{ With voltage and loading constraints } & \multirow{2}{*}{$\begin{array}{l}\text { Changes in } \mathrm{HC}_{2} \\
\text { as compare to } \\
\mathrm{HC}_{1}(\%)\end{array}$} \\
\hline & $\mathrm{HC}_{1}(\mathrm{MW})$ & $\begin{array}{l}\text { Most impacted bus due to } \\
\text { voltage constraint }\end{array}$ & $\mathrm{HC}_{2}(\mathrm{MW})$ & $\begin{array}{l}\text { Most impacted bus/line due to volt- } \\
\text { age and loading constraints }\end{array}$ & \\
\hline $\mathrm{B}_{1}$ & 80.66 & $\mathrm{~B}_{10}$ & 32.46 & $\mathrm{~T}_{1}$ & $60 \downarrow$ \\
\hline $\mathrm{B}_{2}$ & 46.42 & $\mathrm{~B}_{2}$ & 19.81 & $\mathrm{~L}_{1-2}$ & $57 \downarrow$ \\
\hline $\mathrm{B}_{3}$ & 14.93 & $\mathrm{~B}_{3}$ & 14.93 & $\mathrm{~B}_{3}$ & 0 \\
\hline $\mathrm{B}_{4}$ & 13.60 & $\mathrm{~B}_{4}$ & 13.60 & $\mathrm{~B}_{4}$ & 0 \\
\hline $\mathrm{B}_{5}$ & 12.54 & $\mathrm{~B}_{5}$ & 12.54 & $\mathrm{~B}_{5}$ & 0 \\
\hline $\mathrm{B}_{6}$ & 10.17 & $\mathrm{~B}_{6}$ & 10.17 & $\mathrm{~B}_{6}$ & 0 \\
\hline $\mathrm{B}_{7}$ & 6.59 & $\mathrm{~B}_{7}$ & 6.59 & $\mathrm{~B}_{7}$ & 0 \\
\hline $\mathrm{B}_{8}$ & 7.97 & $\mathrm{~B}_{8}$ & 7.97 & $\mathrm{~B}_{8}$ & 0 \\
\hline $\mathrm{B}_{9}$ & 7.69 & $\mathrm{~B}_{9}$ & 7.69 & $\mathrm{~B}_{9}$ & 0 \\
\hline $\mathrm{B}_{10}$ & 7.06 & $\mathrm{~B}_{10}$ & 7.06 & $\mathrm{~B}_{10}$ & 0 \\
\hline $\mathrm{B}_{11}$ & 6.81 & $\mathrm{~B}_{11}$ & 6.81 & $\mathrm{~B}_{11}$ & 0 \\
\hline $\mathrm{B}_{12}$ & 80.82 & $\mathrm{~B}_{14}$ & 33.54 & $\mathrm{~T}_{2}$ & $59 \downarrow$ \\
\hline $\mathrm{B}_{13}$ & 84.66 & $B_{12}$ & 20.52 & $\mathrm{~L}_{12-13}$ & $76 \downarrow$ \\
\hline $\mathrm{B}_{14}$ & 39.82 & $\mathrm{~B}_{14}$ & 21.46 & $\mathrm{~L}_{13-14}$ & $46 \downarrow$ \\
\hline
\end{tabular}

The downward $(\downarrow)$ and upward $(\uparrow)$ signs indicate percentage reduction and increase in the parameter value 
Fig. 11 Hosting capacity without and with loading

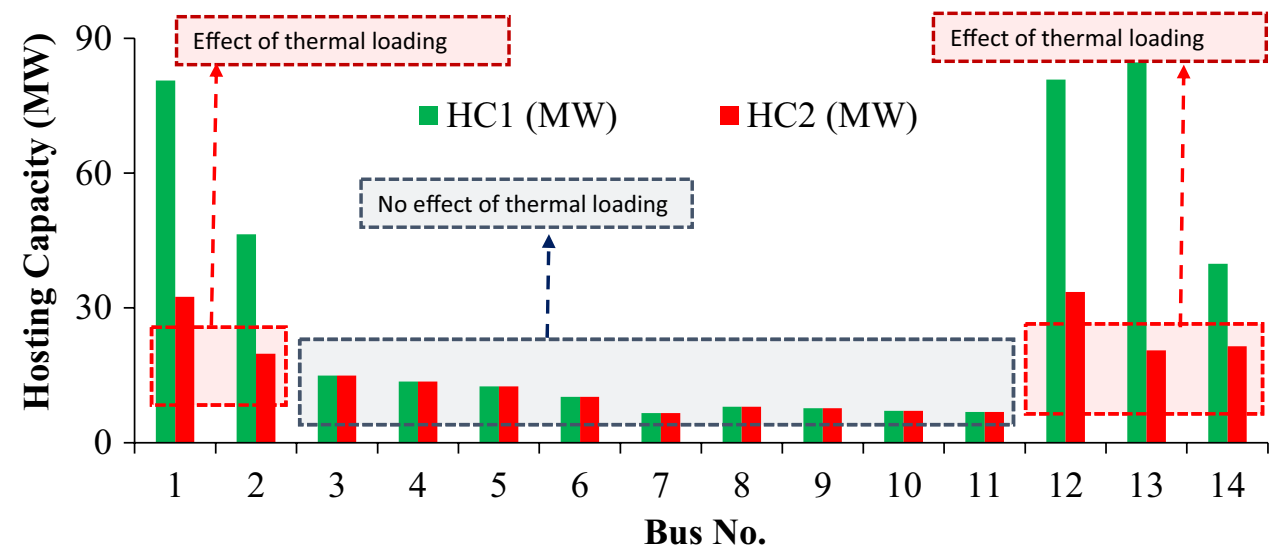

In this study, $7 \mathrm{MW}$ capacity of the solar PV system is distributed into feeder 1 (i.e. $B_{7}, B_{8}, B_{9}$ and $B_{10}$ ). At $B_{7}, B_{9}$ and $B_{10}, 2 \mathrm{MW}$ of the PV system is connected on each bus and simulated in the DRTS. Due to the physical limitations of the testing setup, $1 \mathrm{MW}$ of real hardware (scaled up from the kW range) PV inverter is connected at $B_{8}$ through a PHIL testing setup. This is presented in Fig. 12 and explained in the next section.

\subsection{PHIL testing setup}

To analyze the impact of high PV penetration into the distribution network, a PHIL testing setup is used as shown in Fig. 12. The experimental work is carried out at the Smart Grids Research Unit of the Electrical and Computer Engineering School (Smart RUE) of the National Technical University of Athens.

A PV simulator is used to generate characteristics including irradiance, maximum power point, temperature, etc. The output of the PV simulator is connected to the DC side of the $3 \mathrm{~kW}$ PV inverter. The output of the $3 \mathrm{~kW}$ PV inverter (AC side) is further connected through a linear four-quadrant power amplifier which was upscaled inside DRTS to $1 \mathrm{MW}$ of PV power output at $B_{8}$. Communication between the DRTS and the PV inverter is performed via a communication interface which consists of analogue and digital input/output modules and a real-time target (RTT) computer [17]. The I/O modules communicate through an EtherCat protocol with the RTT, which in turn interfaces these signals directly connected with a MATLAB Workspace.

Battery energy storage of $1 \mathrm{MWh}$ (using DRTS) is integrated at $B_{8}$. The power output of the battery is controlled through a predefined profile of PV + Battery as shown in Fig. 13. In the study, battery charging and discharging are assigned negative (-) and positive (+) signs, respectively. 


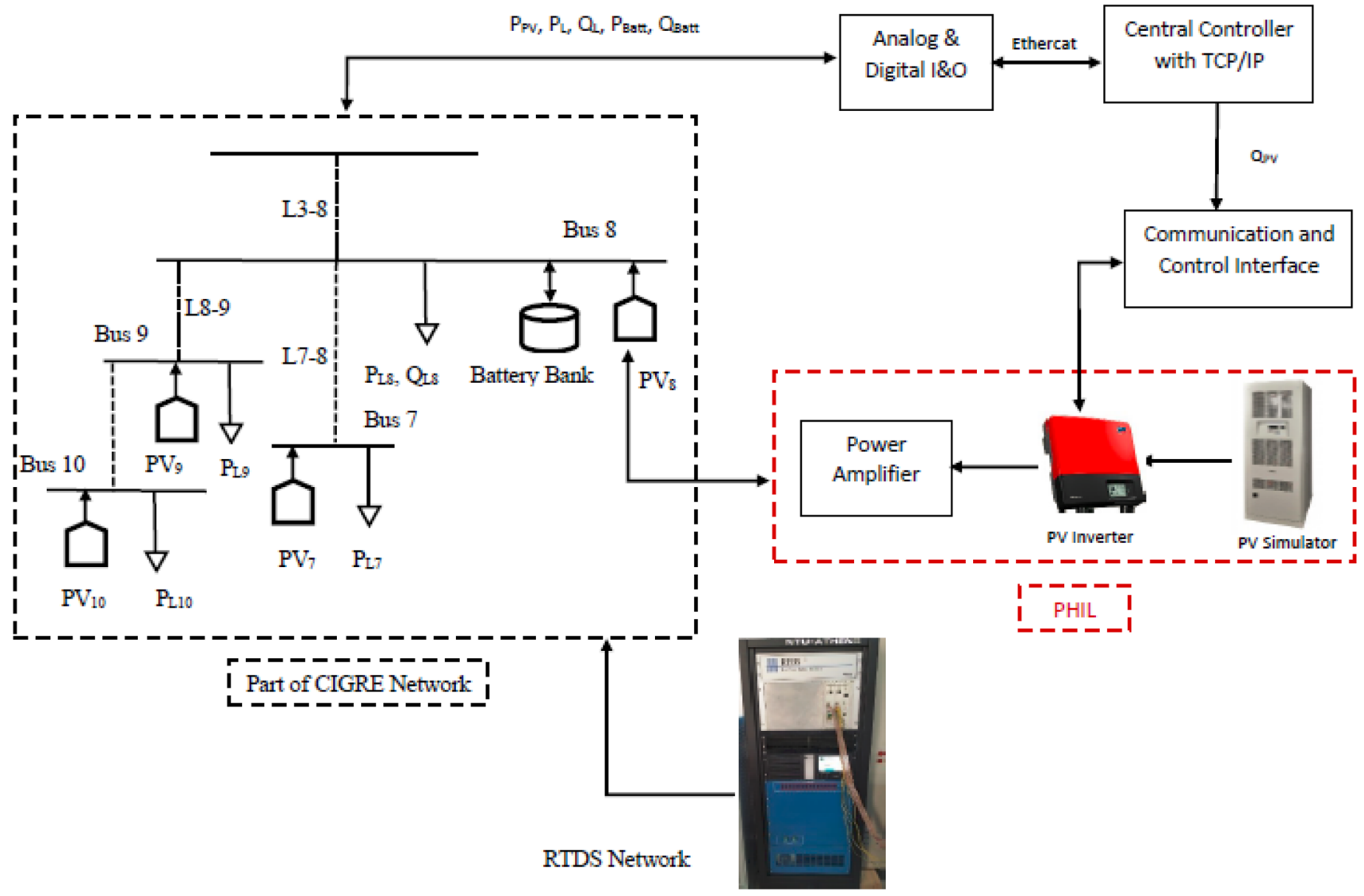

Fig. 12 Laboratory testing setup of PHIL

Fig. 13 PV, battery and $\mathrm{PV}+$ battery profiles

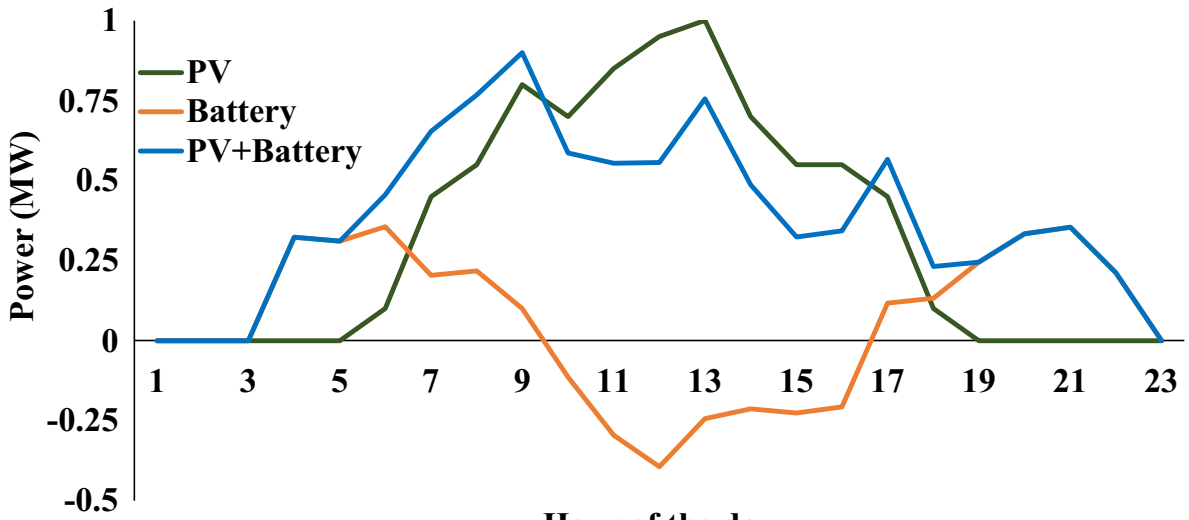

Hour of the day

\subsection{Results and discussion of Case B}

The PV simulator generates its own voltage and current characteristics based on the given input profile. The output of the physical PV inverter is controlled using the PV simulator during the experiment, whereas the other PV systems and loads obtain their respective curves from MATLAB and are simulated using DRTS. The PV simulator is synchronized with MATLAB so that all the PV inverters (one PHIL and the other three simulated in DRTS) follow the same irradiance profile. The results of the PHIL testing are compared with the base case scenario (Case A) and presented in the following section.

In Group A, the voltage of six buses $\left(V_{1}\right.$ to $\left.V_{6}\right)$ and loading of five lines $\left(L_{1-2}, L_{2-3}, L_{3-4}, L_{4-5}\right.$ and $\left.L_{5-6}\right)$ are shown in Figs. 14 and 15, respectively. It is observed from Fig. 14 that 
Fig. 14 Variation in bus voltages of Group A in Case B
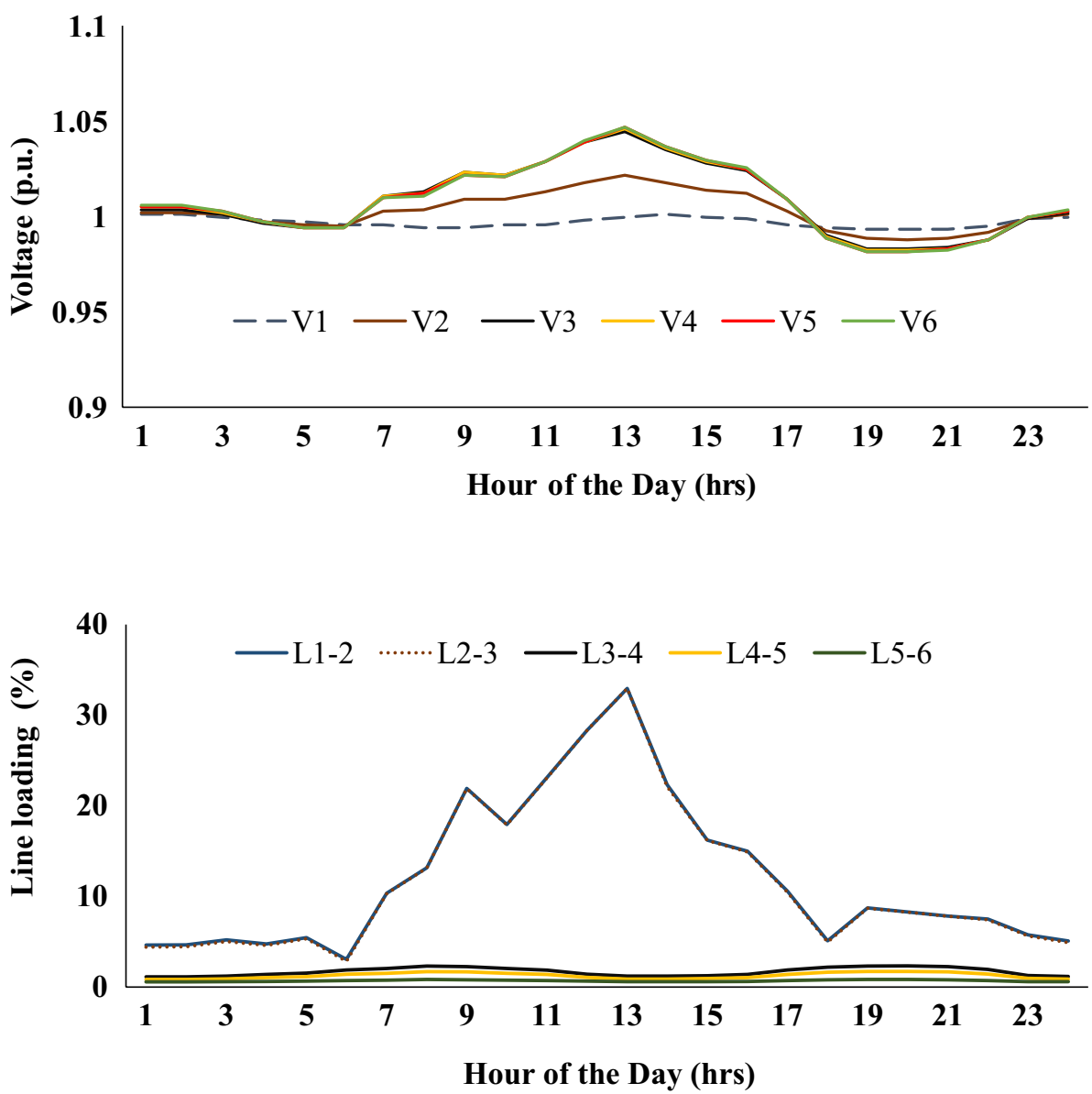

the bus voltages (i.e. $V_{1}$ to $V_{6}$ ) never fall below 0.98 p.u.; however, the maximum voltage reaches 1.05 p.u. The lowest voltage appears during the nighttime peak demand hours (20:00 to 21:00). It is observed that the integration of PV at buses $B_{7}, B_{8}, B_{9}$ and $B_{10}$ improves the voltage profile during the morning peak hours (08:00 to 09:00). The minimum voltage during the daytime is increased from 0.98 p.u. (Case A) to 0.99 p.u. (Case B). However, during the peak daytime hours, the maximum voltage is increased by $5 \%$ as compared to Case A. It is observed that in the different circumstances, the bus voltages do not violate the defined voltage regulation criteria (i.e. $0.90 \leq V_{i} \leq 1.10$ ).

The line loadings of Group A are presented in Fig. 15. It is observed that the maximum line loading is 34\% (i.e. $25 \%$ higher than Case $A$ ) for the lines $L_{1-2}$ and $L_{2-3}$. However, the loadings of the remaining lines $\left(L_{3-4}, L_{4-5}\right.$ and $\left.L_{5-6}\right)$ remain below $2 \%$ throughout the day. This indicates that the PV array connected to the buses $B_{7}, B_{8}, B_{9}$ and $B_{10}$ does not affect the line loading of $L_{3-4}, L_{4-5}$ and $L_{5-6}$, as these lines are connected with a separate string to bus $B_{3}$, and therefore the line loadings remain within the defined limit.

In Group B, the voltage of five buses $\left(V_{7}\right.$ to $\left.V_{11}\right)$ and loading of five lines $\left(L_{7-8}, L_{8-9}, L_{9-10}, L_{10-11}\right.$ and $\left.L_{3-8}\right)$ are shown in Figs. 16 and 17, respectively. The maximum voltages of the buses $\left(B_{7}\right.$ to $B_{11}$ ) are recorded and show an increase of $9 \%$ more (i.e. 1.09 p.u.) as compared to Case A. However, the minimum bus voltage is 0.98 p.u. during nighttime (19:00 to 21:00). Although the voltage of five buses $\left(B_{7}\right.$ to $\left.B_{11}\right)$ is within the defined voltage regulation criteria (i.e. $0.90 \leq V_{i} \leq 1.10$ ), a further increase in PV capacity may exceed the voltage limit.

In Group $B$, the maximum loadings of lines $L_{3-8}$ and $L_{8-9}$ are $33 \%$ (i.e. $28 \%$ higher than Case A) and $21 \%$ (i.e. $17 \%$ higher than Case A), respectively. However, the loadings of the remaining lines (e.g. $L_{7-8}, L_{9-10}$ and $L_{10-11}$ ) are below $11 \%$ throughout the day. The loading of line $L_{3-8}$ is influenced by the load connected to the buses $\left(B_{7}, B_{8}, B_{9}, B_{10}\right.$ and $\left.B_{11}\right)$, and therefore the loading of line $L_{3-8}$ is high as compared to the other line loadings $\left(L_{7-8}, L_{9-10}\right.$ and $\left.L_{10-11}\right)$. It is observed from Fig. 17 that all the lines (except $L_{10-11}$ ) follow the PV generation curve, but because no PV is connected to bus $B_{11}$, the loading curve of line $L_{10-11}$ is not influenced by PV. It is also observed that the line loadings are within the defined limit (i.e. $\leq 100 \%$ ).

In Group $C$, three buses $\left(B_{12}, B_{13}\right.$ and $\left.B_{14}\right)$ and two lines ( $L_{12-13}$ and $\left.L_{13-14}\right)$ are connected to feeder 2 , and no $P V$ is integrated with this feeder. Therefore, bus voltages $\left(V_{12}\right.$, $V_{13}$ and $\left.V_{14}\right)$ and line loadings $\left(L_{12-13}\right.$ and $\left.L_{13-14}\right)$ are not 
affected in this case. The bus voltages $\left(V_{12}, V_{13}\right.$ and $\left.V_{14}\right)$ and line loadings $\left(L_{12-13}\right.$ and $\left.L_{13-14}\right)$ follow the same characteristics as shown in Figs. 7 and 8, respectively.

The variation in transformer loadings $\left(T_{1}\right.$ and $T_{2}$ ) on a typical day is shown in Fig. 18. The loading of transformer $T_{1}$ during the daytime (09:00 to 18:00) is reduced from $29 \%$ (Case $A$ ) to $19 \%$, whereas maximum loading during nighttime (19:00 to $21: 00)$ is the same as in the base case scenario (Case A). It is observed that when integrating the PV system into feeder 1 , the transformer loading $T_{1}$ is reduced, as generated PV power is injected into the grid and is used to meet local demand. The average energy loading of transformer $T_{1}$ is also reduced from $17 \%$ (Case A) to $14 \%$. The loading of transformer $T_{2}$ does not change, as PV is not connected to feeder 2 , and it represents the same characteristics as those of Case A (Fig. 9).
Fig. 16 Variation in bus voltages of Group B in Case B

Fig. 17 Variation in line loadings of Group B in Case B
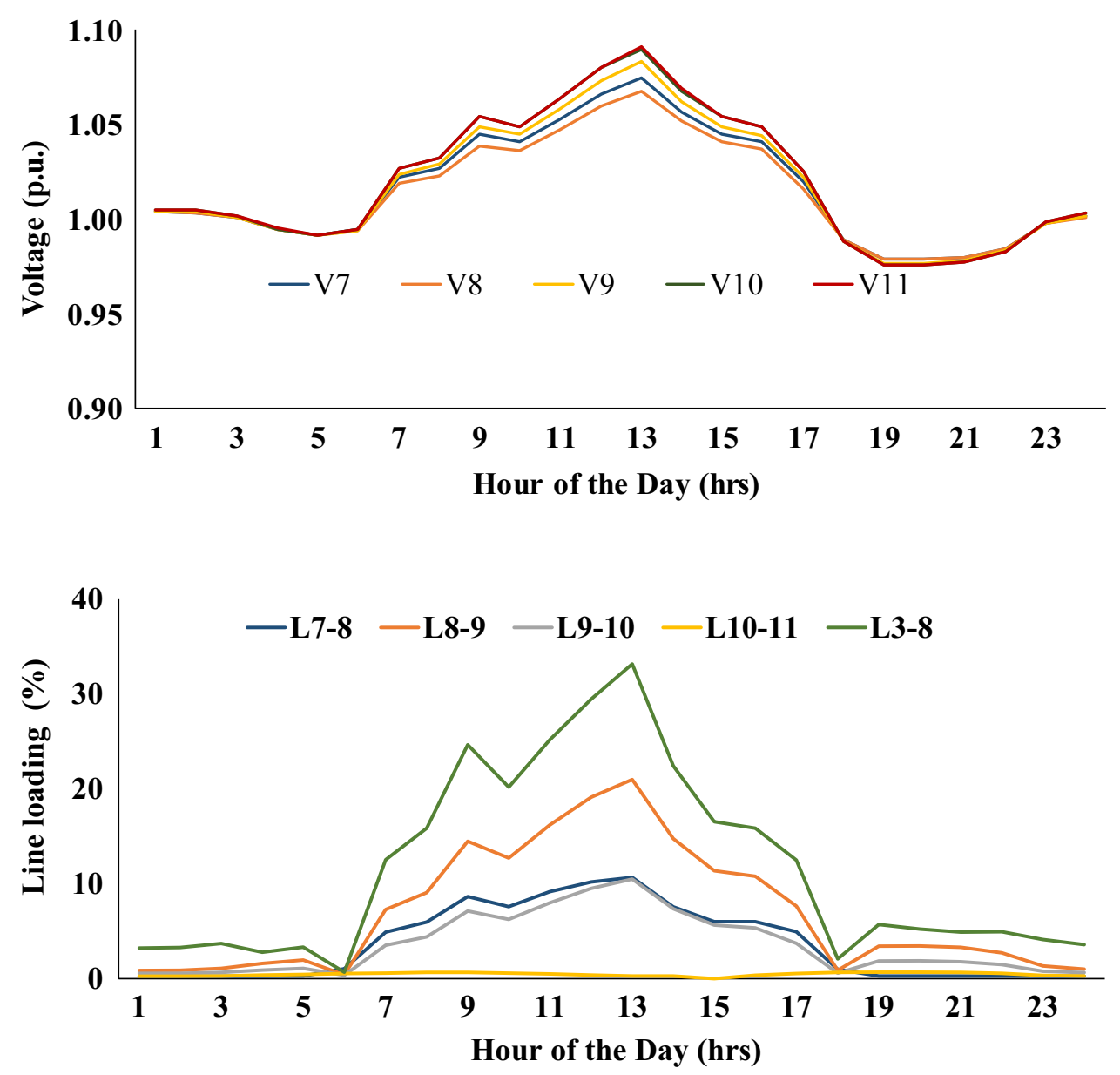

Fig. 18 Variation in transformer loadings in Case B

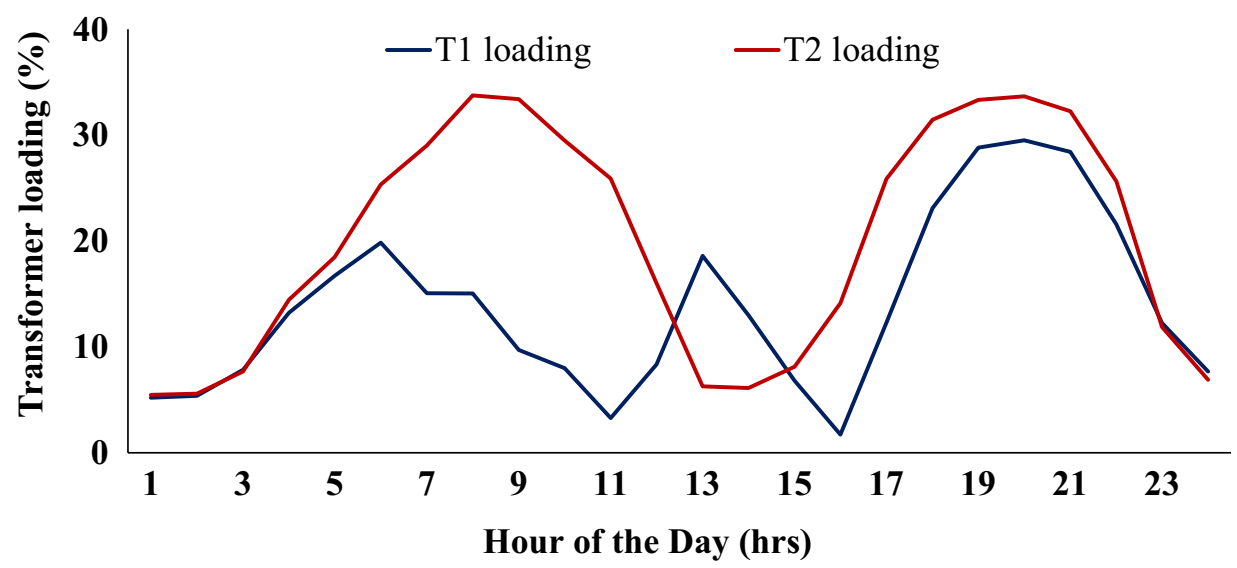


In this section, $\mathrm{PV}$ systems are integrated at buses $B_{7}$, $B_{8}, B_{9}$ and $B_{10}$, and their impacts on the bus voltages, loading of lines and transformer loading are analyzed. Major impacts of PV integration are observed on the voltage profiles and line loadings. It is observed that the bus voltages $\left(V_{7}\right.$ to $\left.V_{11}\right)$ in feeder 1 increased by $9 \%$, and the maximum loading of line $L_{3-8}$ is increased by $28 \%$ as compared to Case A. The average loading of transformer $T_{1}$ is decreased by $3 \%$, and there is no change in the loading of transformer $T_{2}$. It is clearly observed that integrating more $\mathrm{PV}$ at the buses $\left(B_{7}, B_{8}, B_{9}\right.$ and $\left.B_{10}\right)$ may contribute in violating the defined voltage regulation criteria. Therefore, it is essential to test appropriate mitigation techniques to address the voltage rise problem within the distribution network.

In the next section, the QV droop control strategy is used in the PV inverter to test the dynamics of the system in real-time conditions using the power hardware-in-loop test method. A comparative analysis is carried out with and without droop control strategies in Sect. 5.

\section{Validation of QV droop technique using DRTS and PHIL methods (Case C)}

In this section, the application of the droop control concept is explored to improve the voltage profiles so that more PV can be connected to the distribution network. Here, the QV droop control strategy is used in the PV inverter and in the battery's control system. The QV droop control helps to mitigate voltage errors and increase the $\mathrm{HC}$ of the PV in the network by injecting or absorbing reactive power as a result of changes in the bus voltage. The extent of the inverter's response is based on the configured parameters of the droop controller, i.e. the voltage dead-bands, $Q_{\min }$ and $Q_{\max }$ gain of voltage droop as shown in Fig. 19. The fixed QV droop characteristic curve is considered in this work, and a droop control strategy is used in the hardware PV inverter to test the dynamics of the system in real-time conditions based on a PHIL setup as shown in Fig. 12. The QV droop control strategy is also used in the other $\mathrm{PV}$ systems ( $\mathrm{PV}_{7}, \mathrm{PV}_{9}$ and $\mathrm{PV}_{10}$ ) connected to the buses $B_{7}, B_{9}$ and $B_{10}$, and it has the same characteristics as those considered for $\mathrm{PV}_{8}$.

After using the QV droop control strategy, the reactive power contribution from the $\mathrm{PV}$ systems (i.e. $\mathrm{PV}_{7}, \mathrm{PV}_{8}, \mathrm{PV}_{9}$ and $P V_{10}$ ) and the battery at bus $B_{8}$ are recorded, and their values are shown in Fig. 20. It is observed that reactive power support is provided during the daytime when the voltage rise problem appears. The reactive power absorption from $\mathrm{PV}_{10}$ is the highest, whereas $\mathrm{PV}_{7}$ and $\mathrm{PV}_{8}$ have the lowest reactive power absorption. Since $\mathrm{PV}_{8}$ absorbs enough reactive power to improve the voltage profile, the reactive power contribution from the battery energy storage is almost zero. The improvement in the voltage profiles compared with the results obtained in Sect. 5 (Case B) and the group-wise results and analysis are presented in the following section.

\subsection{Results and discussion of Case $C$}

In Case $C, P V$ is integrated at the buses $B_{7}, B_{8}, B_{9}$ and $B_{10}$ network, and the QV droop control strategy is used to analyze the system dynamics in real-time conditions. The output of the PV inverter is controlled using the PV simulator, whereas the simulated PVs and loads obtain their respective curve values from MATLAB. The $P V$ simulator is synchronized with MATLAB, so that all PV inverters $\left(P V_{7}\right.$, $\mathrm{PV}_{8}, \mathrm{PV}_{9}$ and $\mathrm{PV}_{10}$ ) follow the same irradiance profile. The results obtained from Case $C$ are analyzed in the following section.

IIn Group $A$, the voltage of six buses $\left(V_{1}\right.$ to $\left.V_{6}\right)$ and loading of five lines $\left(L_{1-2}, L_{2-3}, L_{3-4}, L_{4-5}\right.$ and $\left.L_{5-6}\right)$ are shown in Figs. 21 and 22, respectively. It is observed from Fig. 21 that the maximum bus voltage is reduced from 1.05 p.u. (Case B) to 1.02 p.u., and the voltages of all six buses $\left(V_{1}\right.$ to $\left.V_{6}\right)$ never fall below 0.99 p.u. The lowest voltage of 0.99 p.u. appears during the peak demand hours (19:00 to 21:00).
Fig. 19 QV droop characteristics

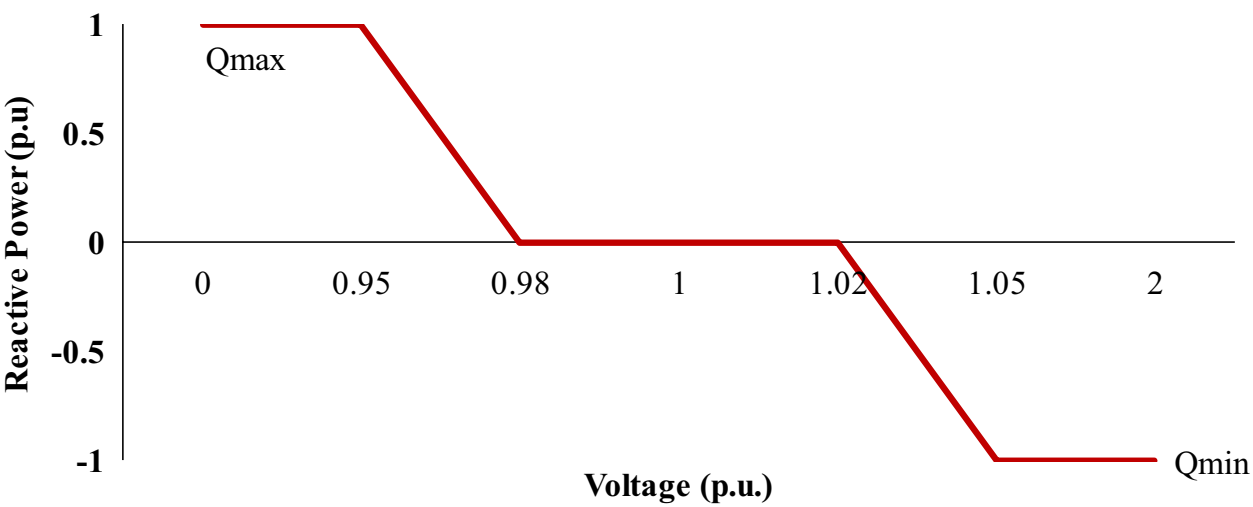

SN Applied Sciences A SPRINGER NATURE journa 
Fig. 20 Reactive power from PV connected at $B_{7}, B_{8}, B_{9}$ and $B_{10}$

Fig. 21 Variation in bus voltages of Group A in Case C

Fig. 22 Variation in line loadings of Group A in Case C
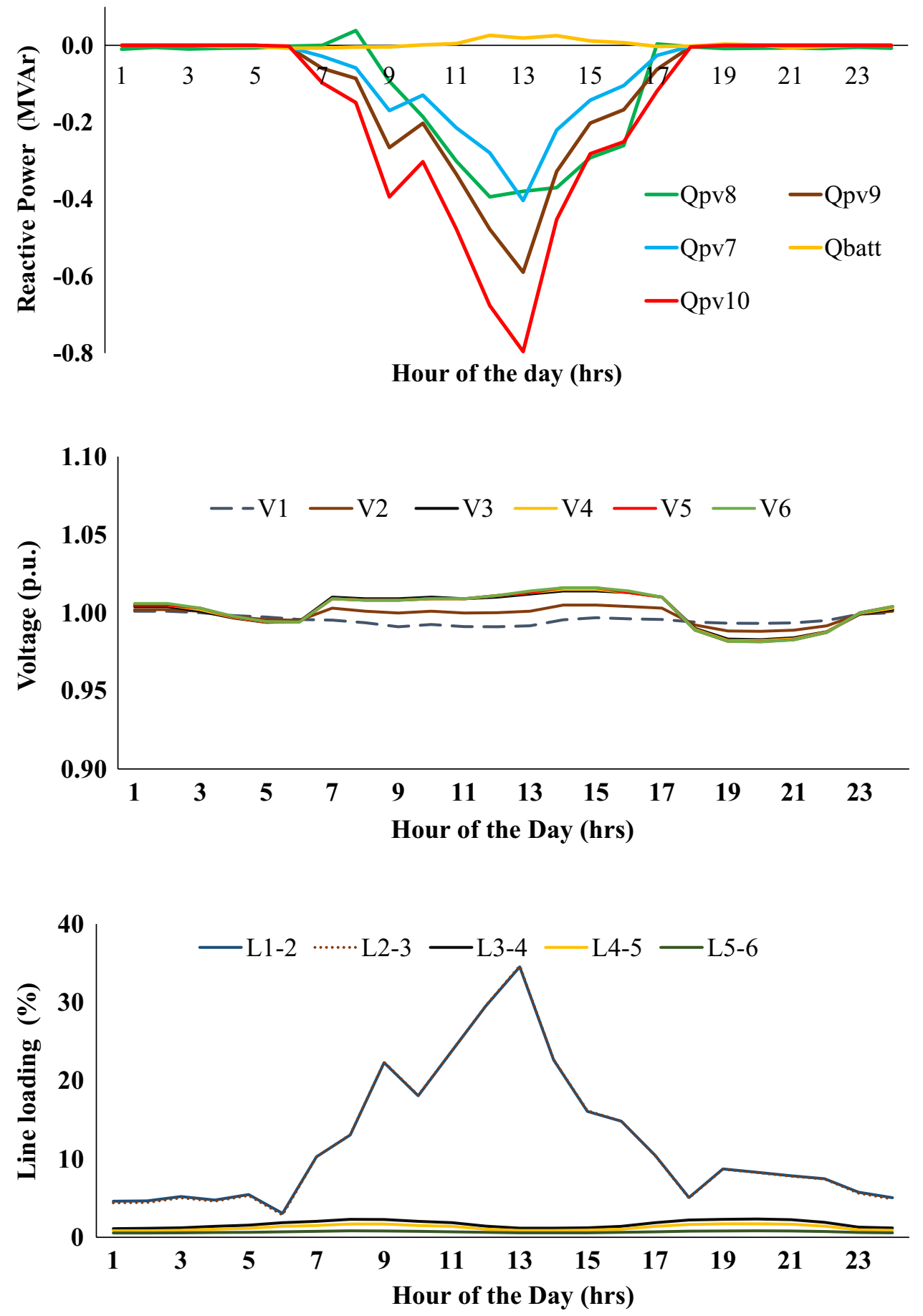

This indicates that the voltage profile is improved by using the droop control strategy with the PV inverter.

It is observed from Fig. 22 that the loading curve follows the same characteristics as shown in Fig. 15 (Case B). The maximum line loading observed is 35\% (i.e. $1 \%$ higher than that of Case B) for the lines $L_{1-2}$ and $L_{2-3}$, whereas the maximum loadings of the remaining lines (e.g. $L_{3-4}, L_{4-5}$ and $L_{5-6}$ ) are almost the same as those of Case $B$ and remain below $2 \%$ throughout the day.
In Group B, the voltage of five buses $\left(V_{7}\right.$ to $\left.V_{11}\right)$ and loading of five lines $\left(L_{7-8}, L_{8-9}, L_{9-10}, L_{10-11}\right.$ and $\left.L_{3-8}\right)$ are shown in Figs. 23 and 24. In Case $B$, the maximum voltage rise issues are observed in the buses $\left(B_{7}, B_{8}, B_{9}\right.$ and $B_{10}$ ), but after using the QV droop control strategy, the maximum voltage is reduced from 1.09 to $1.04 \mathrm{p} . \mathrm{u}$. The droop control strategy used through the DRTS and PHIL method at $B_{8}$ is verified. It is observed that the QV droop 
Fig. 23 Variation in bus voltages of Group B in Case C

Fig. 24 Variation in line loadings of Group B in Case C
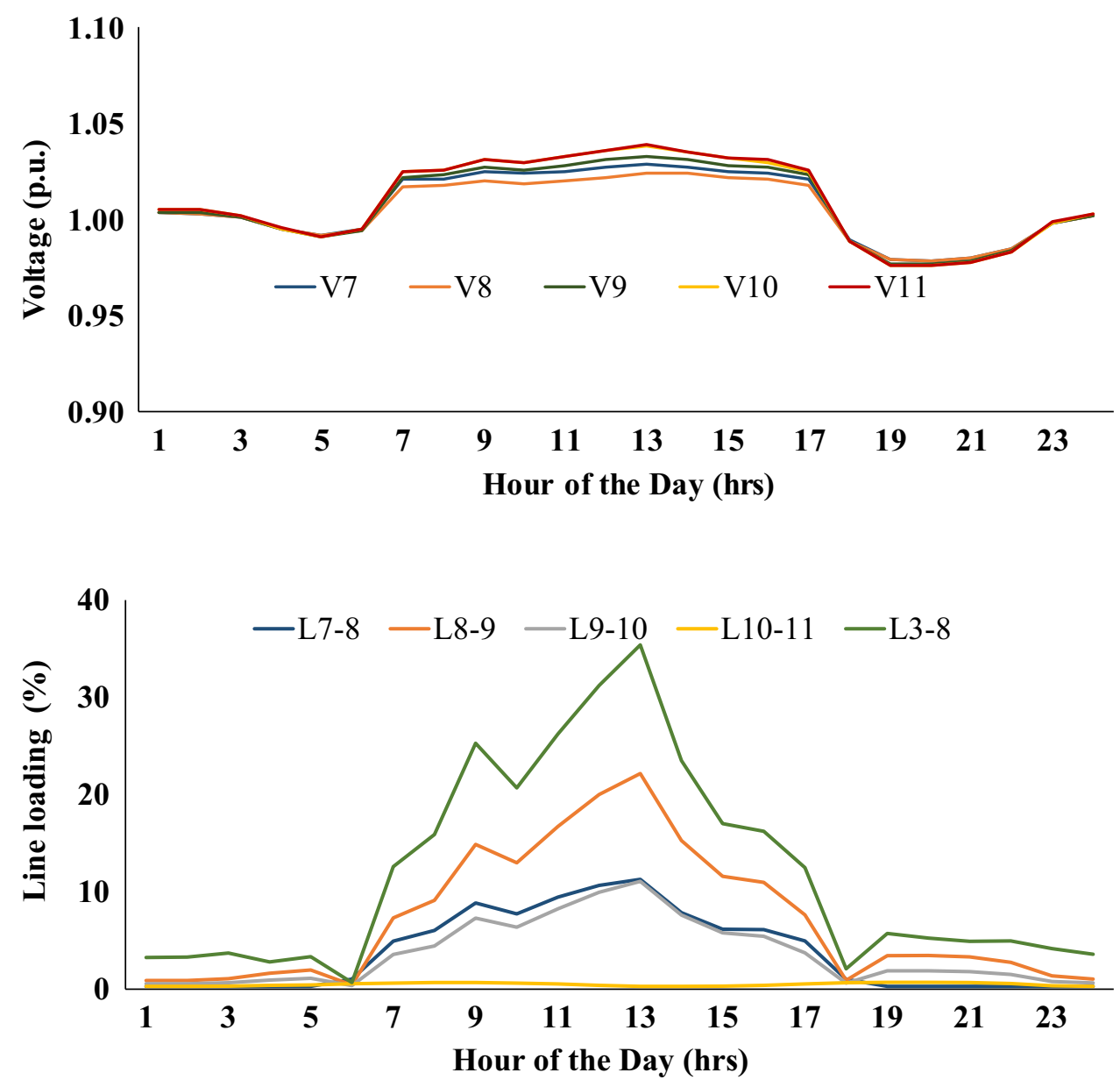

control strategy can help to improve the voltage profile during a high PV penetration scenario.

In Group B, it is observed from Fig. 24 that the loading curve follows the same characteristics as for Case $B$ (Fig. 17). The maximum loadings of lines $L_{3-8}$ and $L_{8-9}$ for Case $C$ are $35 \%$ and $22 \%$, respectively, and these line loadings are only $1 \%$ higher than those of Case B (without QV droop control). There is also no significant change observed for loadings of the remaining lines (e.g. $L_{7-8}, L_{9-10}$ and $\left.L_{10-11}\right)$, and it remains below $12 \%$ throughout the day. A small increase in the line loading appears due to the reactive power support provided by the PV inverters.

In Group $C$, three buses $\left(B_{12}, B_{13}\right.$ and $\left.B_{14}\right)$ and two lines ( $L_{12-13}$ and $\left.L_{13-14}\right)$ are connected to feeder 2 , and no PV is integrated with this feeder; therefore, the bus voltages $\left(V_{12}, V_{13}\right.$ and $\left.V_{14}\right)$ and line loadings $\left(L_{12-13}\right.$ and $\left.L_{13-14}\right)$ are not affected in this case. The bus voltages $\left(V_{12}, V_{13}\right.$ and $\left.V_{14}\right)$ and line loadings ( $L_{12-13}$ and $\left.L_{13-14}\right)$ follow the same characteristics as shown in Figs. 7 and 8, respectively.

The variation in transformer loadings $\left(T_{1}\right.$ and $\left.T_{2}\right)$ in a typical day is shown in Fig. 25. The loading characteristics of transformer $T_{2}$ do not change, as the PV is not connected to feeder 2 and represents the same characteristics as shown in Fig. 9 (Case A). However, the maximum loading of transformer $T_{1}$ during the morning peak hours ( 08:00 and 09:00) is increased by $1 \%$ compared to Case B (without the QV droop control strategy), whereas maximum loading during the night peak hours (19:00 to 21:00) is the same as that of Case B. The average daily energy loading of transformer $T_{1}$ increases from 14\% (Case B) to $15 \%$.

In this section, the PV systems are integrated at buses $B_{7}, B_{8}, B_{9}$ and $B_{10}$, and the QV droop control strategy is used in all inverters to improve the voltage profiles. It is observed that by using the QV droop control strategy, the maximum bus voltage is reduced from 1.09 p.u. (Case B) to 1.04 p.u. (Case C). The average loading of lines and transformers is increased by only $1 \%$ with the QV droop control strategy. It is clearly observed that by using the QV droop control strategy, more PV can be integrated at the buses $\left(B_{7}, B_{8}, B_{9}\right.$ and $\left.B_{10}\right)$, and PV energy can be used to meet the local demand.

In this section, the voltage rise problem is addressed by using the QV droop control strategy. However, the CIGRE distribution network also has the potential to operate as a mesh network by connecting the two feeders through switch $S_{1}$. This study is further extended to analyze the 
Fig. 25 Variation in transformer loadings in Case $\mathrm{C}$

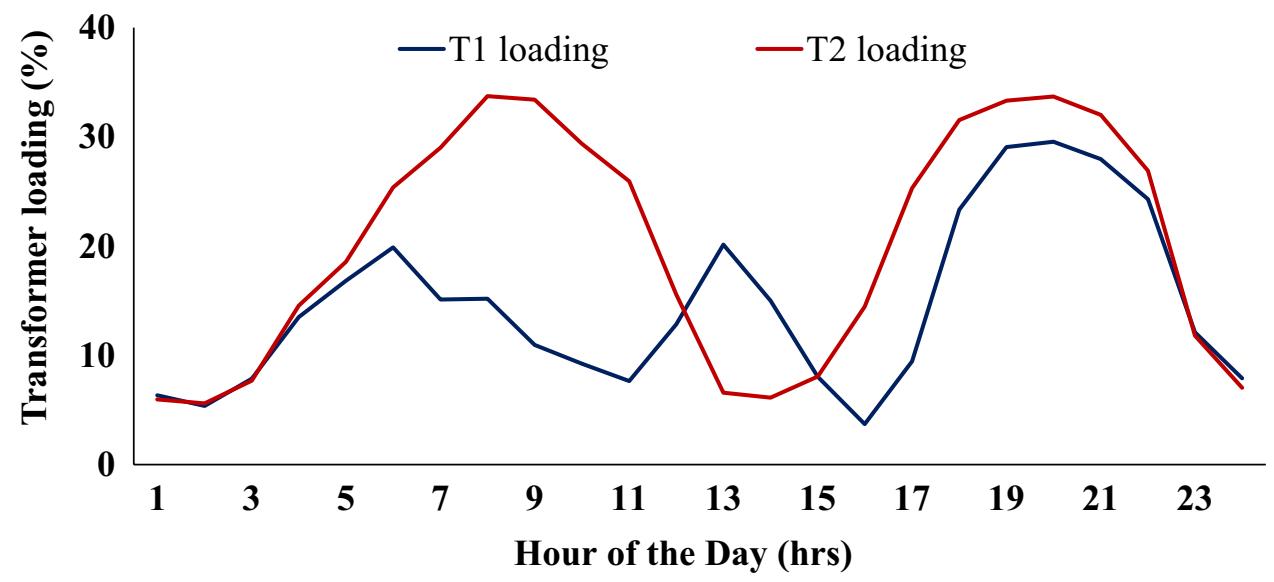

impacts of high PV penetration on the mesh type distribution network, and its results are compared with those of the radial network (Case C, PV integration with QV droop) and presented in the next section.

\section{Impact of PV penetration within mesh network (Cases D and E)}

Switch $S_{1}$ is important, as it is connected between both feeders; therefore, a mesh network could be created by closing switch $S_{1}$. In this section, a mesh network is formed and two experiments (Cases D and E) are carried out. In Case $D$, the distribution network configuration is the same as in Case B, but switch $S_{1}$ is closed, whereas Case E represents the same distribution network configuration as Case $C$, and switch $S_{1}$ is closed. This means that Case $D$ analyzes the impacts of only the radial network formation $\left(S_{1}\right.$ closed) during high PV penetration, but in Case $E$, the cumulative impact of the QV droop control strategy and formation of the radial network $\left(S_{1}\right.$ closed) is analyzed. In order to conduct the experiment, the same methodology is used as explained in Sect. 4.1. The group-wise results are analyzed and discussed in the following section.

\subsection{Comparison of Cases D and E with B}

In Group $A$, the voltage of six buses $\left(V_{1}\right.$ to $\left.V_{6}\right)$ for Cases $D$ and $E$ are shown in Figs. 26 and 27, respectively. In Case $B$, the maximum voltage rise of Group $A$ in feeder 1 is 1.05 p.u. (see Fig. 14), and it decreases to 1.04 p.u. when the distribution network is converted to a radial network (Case D), as shown in Fig. 26. However, in Case E, the cumulative effect of both the radial network and QV droop control strategy reduce the maximum voltage from 1.05 p.u. (Case B) to 1.02 p.u. This shows that a QV droop control strategy and mesh network formation together effectively improve the voltage profiles of the distribution network.

The maximum change in the loading of lines $L_{1-2}$ and $L_{2-3}$ is observed in Group A; therefore, a comparison of only line loading $L_{2-3}$ for Cases $B, D$ and $E$ is considered for analysis purposes, and is shown in Fig. 28. It is observed from Fig. 28 that loading of line $L_{2-3}$ follows the same characteristics for all three cases (B, D and $E$ ); however, maximum loadings of line $L_{2-3}$ for Case $D$ and Case $E$ are reduced from
Fig. 26 Bus voltages of Group $A$ in Case D

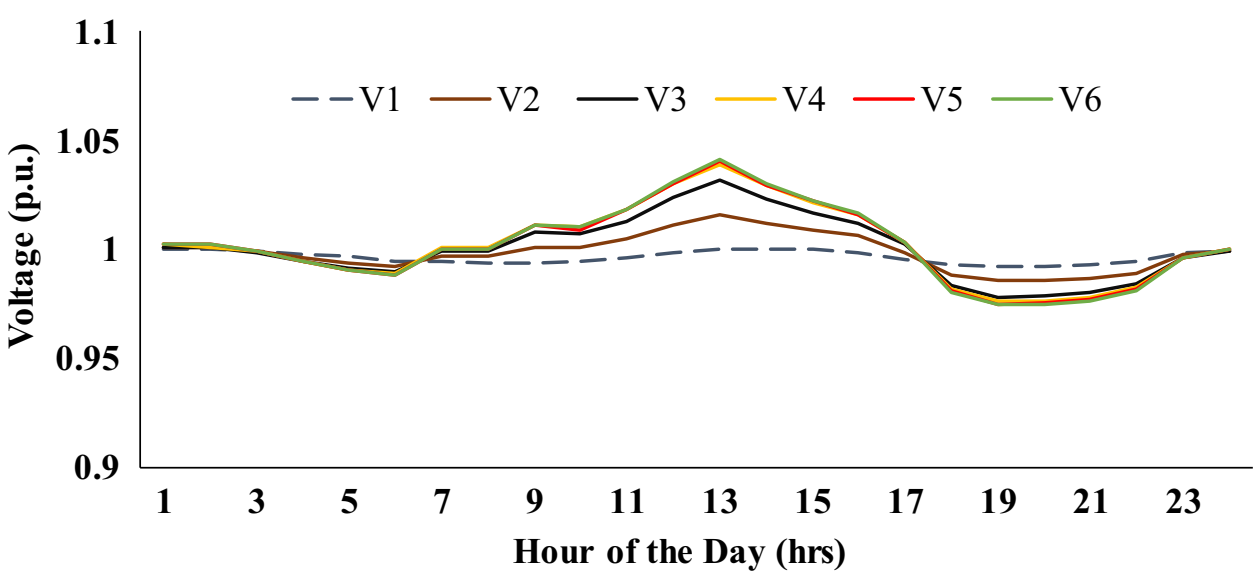


$33 \%$ (Case B) to $15 \%$ and $16 \%$, respectively. This indicates that creating a mesh network also reduces the overall line loading of feeder 1.

In Group $B$, the bus voltages $\left(V_{7}\right.$ to $\left.V_{11}\right)$ for Cases $D$ and $E$ are shown in Figs. 29 and 30, respectively. In Case B, the maximum voltage rise in feeder 1 is 1.09 p.u. (see Fig. 16), and it decreases to 1.05 p.u. when the distribution network is converted to a radial network (Case D), as shown in Fig. 29. However, in Case E, the cumulative effect of the radial network and the QV droop control strategy reduce the maximum voltage from 1.09 p.u. (Case B) to 1.03 p.u. This shows that a QV droop control strategy and mesh network formation together effectively improve the voltage profiles of the distribution network.

The maximum changes in the loading of line $L_{3-8}$ are observed in Group B, and therefore a comparison of only
Fig. 27 Bus voltages of Group $A$ in Case $E$

Fig. 28 Line loading of $L_{2-3}$ for Cases B, D and E

Fig. 29 Bus voltages of Group $B$ in Case D
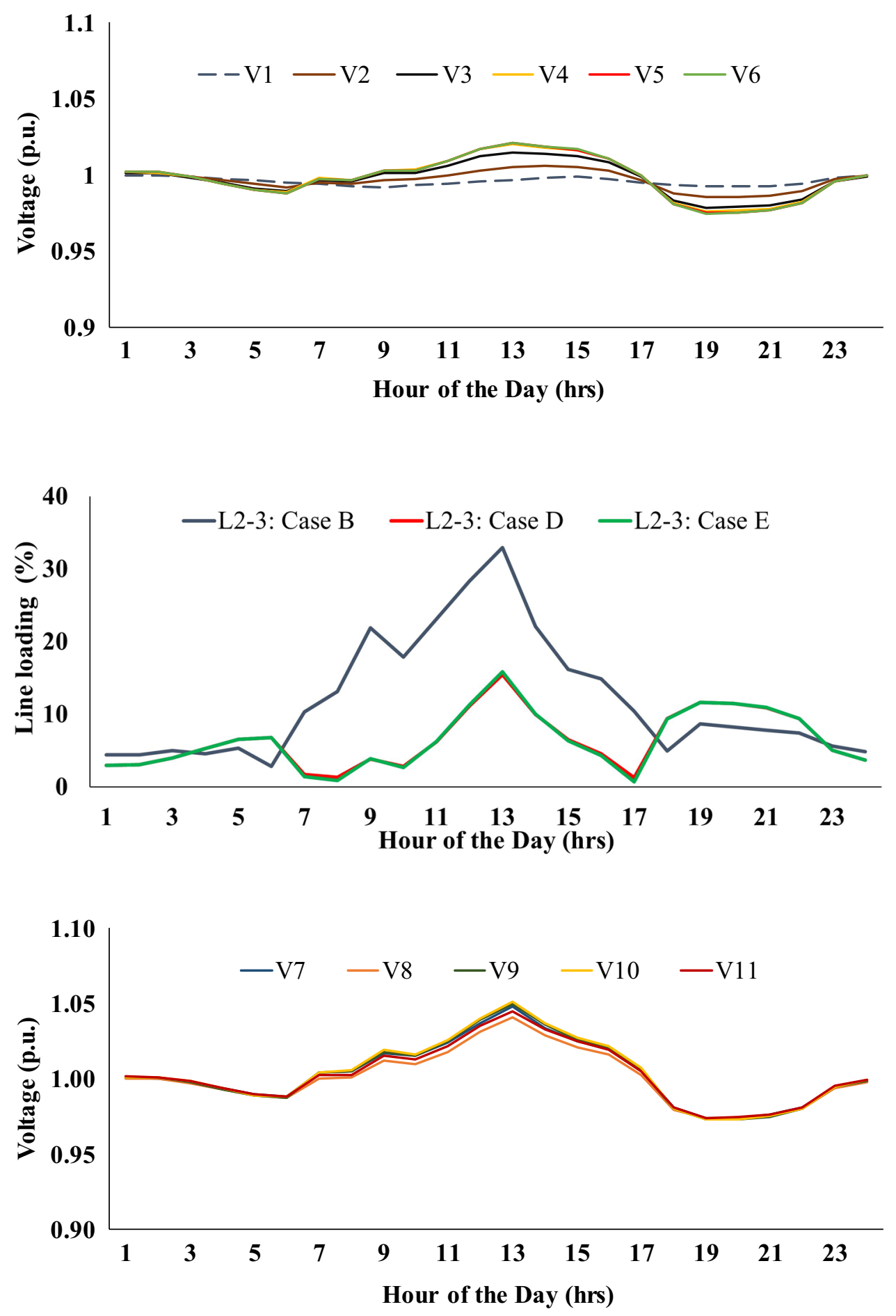

SN Applied Sciences 
line loading $L_{3-8}$ for Cases $B, D$ and $E$ is considered for analysis purposes and is shown in Fig. 31. Here it can be seen that the loading of line $L_{3-8}$ follows the same characteristics for all three cases (Cases B, D and E). However, the maximum loading of line $L_{3-8}$ for Case $D$ and Case $E$ decreases from $33 \%$ (Case B) to $6.7 \%$ and $7 \%$, respectively. This indicates that creating a mesh network reduces the overall line loading of feeder 1.

In Group $C$, bus voltages $\left(V_{12}, V_{13}\right.$ and $\left.V_{14}\right)$ for both Cases $D$ and $E$ are shown in Figs. 32 and 33, respectively. In Case
$B$, the maximum voltage rises of $B_{14}$ in feeder 2 is 0.99 p.u. (see Fig. 7), and it increases to 1.01 when the radial distribution network is converted to a mesh network (Case D) as shown in Fig. 32. The cumulative effect into bus voltage $B_{14}$ due to both the mesh network and QV droop control strategy (Case E) does not result in significant changes to the bus voltage $V_{14}$ (Fig. 33).

The loading of lines $L_{12-13}$ and $L_{13-14}$ in Group $C$ is almost the same; therefore, a comparison of only line loading $L_{13-14}$ for Cases $B, D$ and $E$ is considered for
Fig. 30 Bus voltages of Group $B$ in Case $E$

Fig. 31 Line loading of line $L_{3-8}$ for Cases B, D and E

Fig. 32 Bus voltages of Group $C$ for Case D
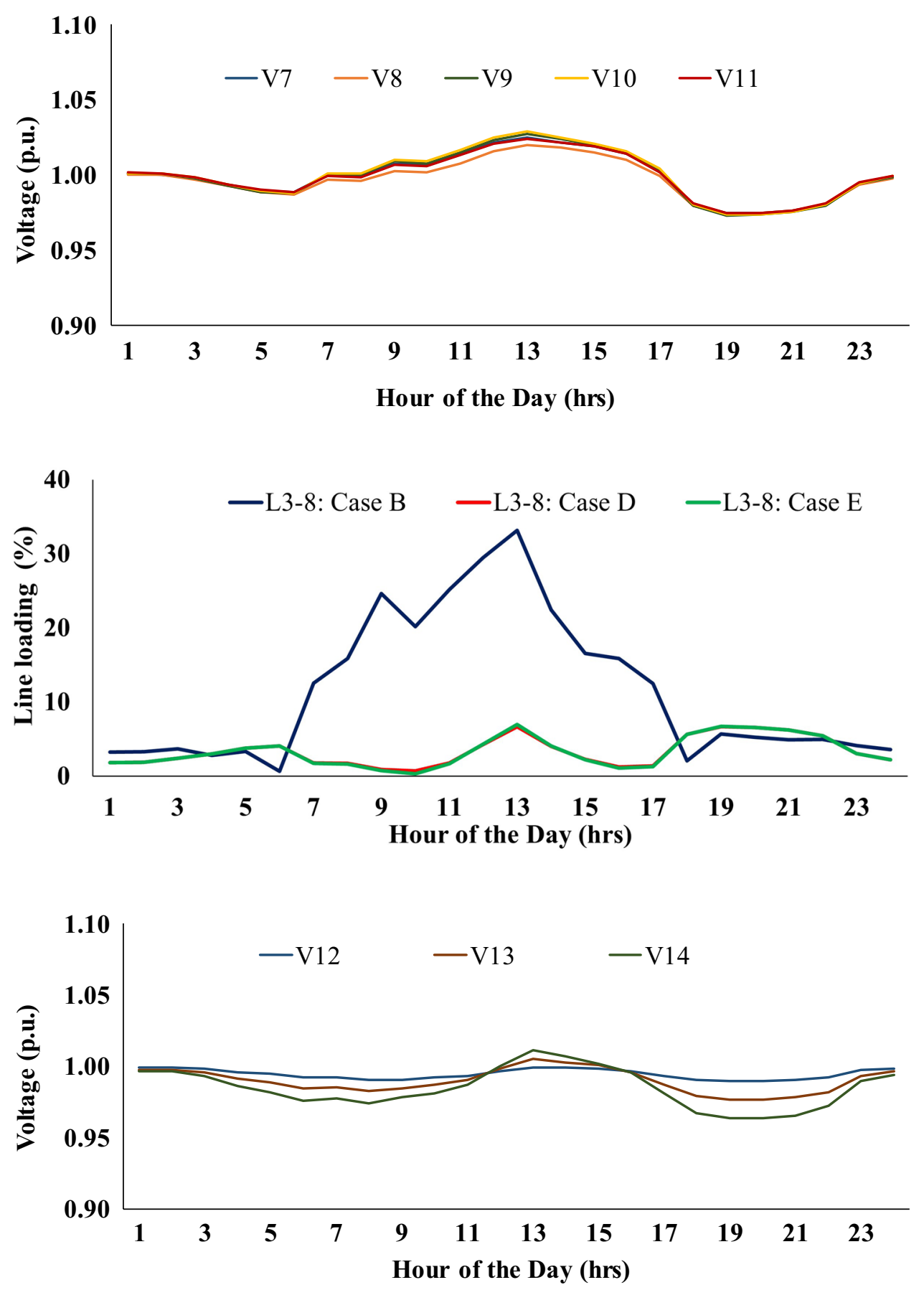
analysis purposes and is shown in Fig. 34. It is observed from Fig. 34 that the loading of line $L_{13-14}$ follows the characteristics of Cases $D$ and $E$, but is different for Case $B$. The maximum line loading for Case $B$ is $18 \%$ and is observed during the morning peak hours (08:00 to 09:00) and evening peak hours (20:00 to 21:00). In Cases $D$ and $E$, the maximum line loading is shifted to the peak daytime hours $(13: 00 \mathrm{~h})$ and is $16 \%$ and $17 \%$ for Cases $D$ and $E$, respectively. The average line loading for Cases $\mathrm{D}$ and $\mathrm{E}$ is reduced from $11 \%$ (Case $\mathrm{B}$ ) to $7 \%$ and $8 \%$, respectively.
The loading of transformer $T_{1}$ for the Cases $B, D$ and $E$ is shown in Fig. 35. By connecting both feeders together through switch $S_{1}$, transformer loading $T_{1}$ is also changed for Case D and Case E as compared to Case B. The maximum transformer loading of $T_{1}$ during morning peak hours (08:00 to $09: 00$ ) increases from $15 \%$ (Case B) to $20 \%$ and $20 \%$ for Cases $D$ and $E$, respectively. However, maximum transformer loading of $T_{1}$ in Case $B$ during the night peak hours (20:00 to $21: 00$ ) decreases by only $1 \%$ for Cases $D$ and $\mathrm{E}$. The transformer loading $T_{1}$ during the peak daytime hours (13:00) decreases from 19\% (Case B) to $11 \%$ and
Fig. 33 Bus voltages of Group C for Case E

Fig. 34 Line loading of $L_{13-14}$ for Cases B, D and E

Fig. 35 Loading of transformer $T_{1}$ for Cases B, D and E
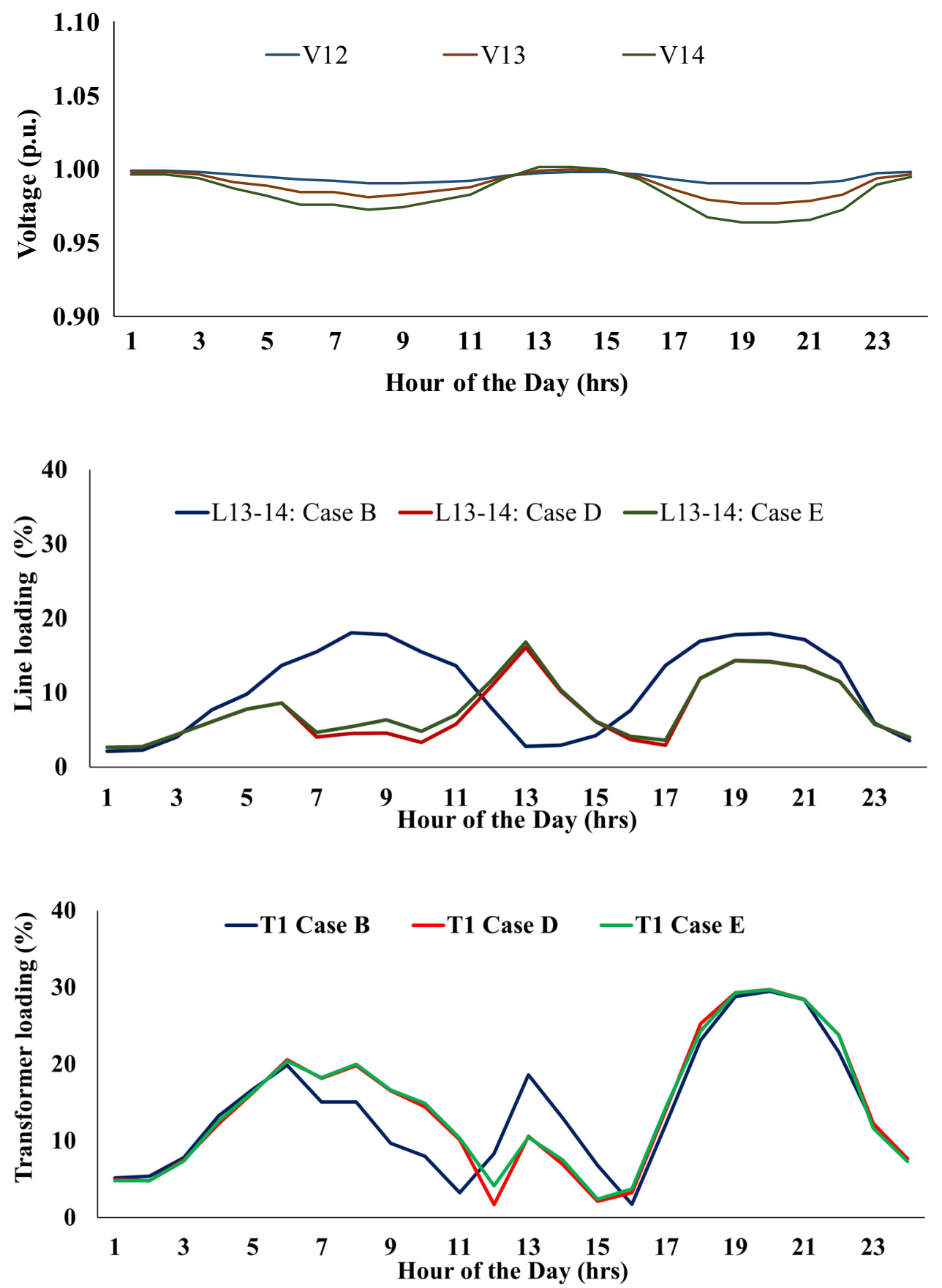

SN Applied Sciences 
$10 \%$ for Case $D$ and Case $E$, respectively. The average daily energy loading of transformer $T_{1}$ is the same for Cases $\mathrm{B}$, $D$ and $E$, at $14 \%$.

The loadings of transformer $T_{2}$ for Cases $B, D$ and $E$ are shown in Fig. 36. The maximum transformer loading of $T_{2}$ for Case B during the morning peak hours (08:00 to 09:00) is decreased from $34 \%$ to $27 \%$ for Cases $D$ and $E$; however, maximum transformer loading of $T_{2}$ for Case $B$ during the night peak hours (19:00 to $21: 00$ ) decreases by only $1 \%$ for Cases $\mathrm{D}$ and $\mathrm{E}$. The transformer loading $T_{2}$ during the peak daytime hours (13:00) is decreased from 6\% (Case B) to $2 \%$ and $4 \%$ for Case $D$ and Case $E$, respectively. The average transformer loading of $T_{2}$ for Case B is $20 \%$ and for Cases $\mathrm{D}$ and $\mathrm{E}$ is $17 \%$ for both. This indicates that by connecting both feeders through switch $S_{1}$, transformer loading $T_{2}$ is reduced by $3 \%$.

\section{Conclusions}

In this paper, the PV hosting capacity within a distribution network was estimated considering network operational parameters (voltage, power line loading). The load variations and simultaneous PV outputs at different buses were considered for a selected CIGRE network. The PV hosting capacity was varied on selected buses of the network to maintain the network operational parameters within the prescribed limits. In scenario $1\left(\mathrm{HC}_{1}\right)$, only the voltage constraint was used with a typical daily load and PV profiles to analyze the PV hosting capacity on the network buses. However, scenario $2\left(\mathrm{HC}_{2}\right)$ considered both voltage and power line loading variations to evaluate the impact of PV hosting capacity on the network buses. It was observed that by considering voltage and loading as constraints, the PV hosting capacity $\left(\mathrm{HC}_{2}\right)$ at buses $B_{1}, B_{2}, B_{12}, B_{13}$ and $B_{14}$ of the selected network was reduced by more than $50 \%$ as compared to the scenario when only voltage was taken as a constraint $\left(\mathrm{HC}_{1}\right)$. It was observed that the network operational constraints had a significant impact in estimating the PV hosting capacity within the distribution network.

In this work, the impacts of PV system integration at selected buses of feeder 1 were analyzed using the DRTS and PHIL testing methods. The results show that the maximum bus voltages $\left(V_{7}\right.$ to $\left.V_{11}\right)$ in feeder 1 are increased by 9\% during the peak daytime hours (13:00) when $2 \mathrm{MW}$ of $\mathrm{PV}$ is connected to each bus $B_{7}, B_{9}$ and $B_{10}$ and $1 \mathrm{MW}$ of $\mathrm{PV}$ at bus $B_{8}$. Moreover, the maximum line loading $\left(L_{1-2}\right.$ and $\left.L_{2-3}\right)$ increased by $24 \%$ as compared to the base case scenario (Case $A$, no PV integration). The integration of PV at feeder 1 also affected the loading curve of transformer $T_{1}$. It was observed that the average loading of transformer $T_{1}$ was reduced from $17 \%$ (Case A, no PV integration) to $14 \%$ (Case B, with PV integration); however, the loading of transformer $T_{2}$ did not change, as no PV was connected to feeder 2.

The voltage rise problem due to integration of PV was addressed using the QV droop control strategy into the PV inverter. It was observed that by using the QV droop control strategy (Case $C$ ) into the PV inverter, the maximum bus voltages $\left(V_{7}\right.$ to $\left.V_{11}\right)$ in feeder 1 decreased to 1.05 p.u. from 1.09 p.u. (Case B, without QV droop control); however, no significant changes were observed in the line loading or transformer loadings. In this work, the operational performance of the mesh type electrical distribution network was compared with the radial type electrical distribution network, in particular in high PV penetration scenarios. It was observed that in a PV-integrated electrical energy network, line loading can be reduced by $20 \%$ if the network is configured from a radial to a mesh type. Also, the QV droop control strategy further improves the voltage profile.

These results will to be useful for electricity distribution companies, industries and policymakers for analyzing the impacts of high PV penetration into a distribution network for future grid operation or grid reinforcement planning.
Fig. 36 Loading of transformer $T_{2}$ for Cases B, D and E

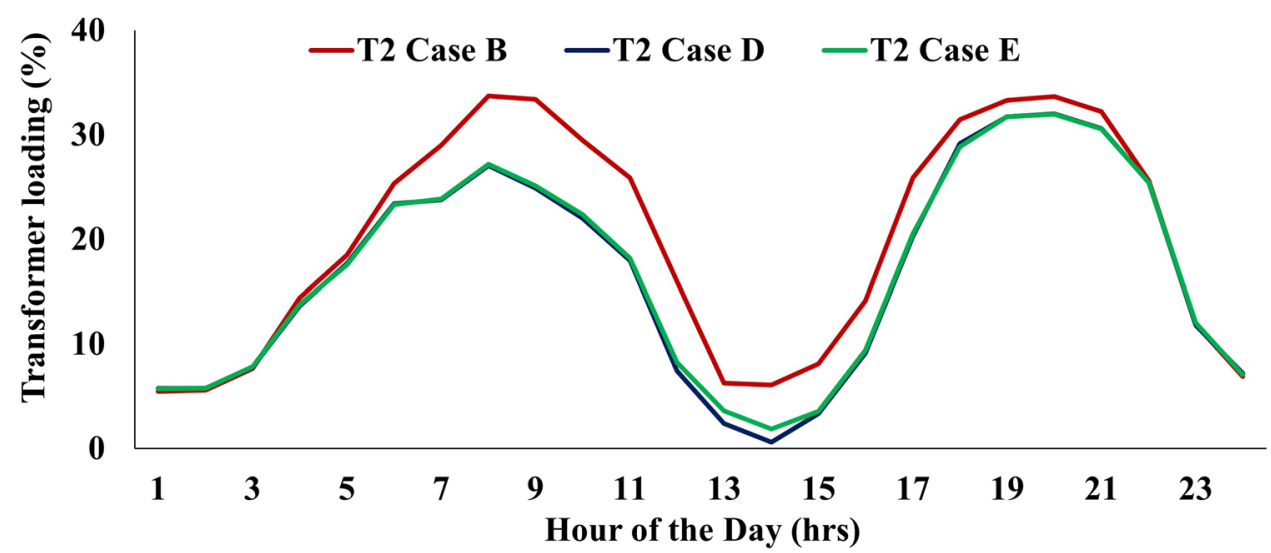


This work will contribute in the analysis of operational risk scenarios with high PV penetration and in implementing mitigation techniques (e.g. QV droop functionality) with further investigation of power quality.

Acknowledgements The authors are grateful to the ERIGrid H2020 Research Infrastructure Project for providing the facilities of SmartRUE Electric Energy Systems Laboratory at National Technical University of Athens (NTUA). The authors acknowledge the technical advice of Professor Nikos Hatziargyriou and his team from NTUA.

\section{Declarations}

Conflict of interest The authors declare that they have no conflict of interest.

Open Access This article is licensed under a Creative Commons Attribution 4.0 International License, which permits use, sharing, adaptation, distribution and reproduction in any medium or format, as long as you give appropriate credit to the original author(s) and the source, provide a link to the Creative Commons licence, and indicate if changes were made. The images or other third party material in this article are included in the article's Creative Commons licence, unless indicated otherwise in a credit line to the material. If material is not included in the article's Creative Commons licence and your intended use is not permitted by statutory regulation or exceeds the permitted use, you will need to obtain permission directly from the copyright holder. To view a copy of this licence, visit http://creativecommons. org/licenses/by/4.0/.

\section{References}

1. Azmi AN, Kolhe M (2015) "Photovoltaic Based Active Generator: Energy Control System Using Stateflow Analysis." 11th International Conference on Power Electronics and Drive Systems, IEEE, pp. 18-22. https://doi.org/10.1109/PEDS.2015.7203433.

2. Navarro BB, Navarro MM (2017) "A Comprehensive Solar PV Hosting Capacity in MV and LV Radial Distribution Networks." IEEE PES Innovative Smart Grid Technologies Conference Europe (ISGTEurope), pp. 1-6, https://doi.org/10.1109/ISGTEurope.2017.82602 10.

3. Atmaja WY, Sarjiya Lesnanto MP, Pramono EY (2019) "Hosting Capacity Improvement Using Reactive Power Control Strategy of Rooftop PV Inverters." IEEE 7th International Conference on Smart Energy Grid Engineering (SEGE), pp. 213-217, https://doi.org/10. 1109/SEGE.2019.8859888.

4. Niederhuemer W, Schwalbe R (2015) "Increasing PV Hosting Capacity in LV Grids with a Probabilistic Planning Approach." International Symposium on Smart Electric Distribution Systems and Technologies (EDST), pp. 537-540, https://doi.org/10.1109/SEDST. 2015.7315266.

5. Saber AY, Khandelwal T, Srivastava AK (2019) "Fast Feeder PV Hosting Capacity Using Swarm Based Intelligent Distribution Node Selection." IEEE Power \& Energy Society General Meeting (PESGM), pp. 1-5, https://doi.org/10.1109/PESGM40551.2019.8973389.

6. Al-Saffar M, Zhang S, Nassif A, Musilek P (2019) "Assessment of Photovoltaic Hosting Capacity of Existing Distribution Circuits." IEEE Canadian Conference of Electrical and Computer Engineering (CCECE), pp. 1-4, https://doi.org/10.1109/CCECE.2019.8861957.

7. Zhang G, Shi Y, Maleki A, Rosen MA (2020) Optimal location and size of a grid-independent solar/hydrogen system for rural areas using an efficient heuristic approach. Renew Energy 156:12031214. https://doi.org/10.1016/j.renene.2020.04.010
8. Zhang W, Maleki A, Birjandi AK, Alhuyi Nazari M, Mohammadi $\mathrm{O}(2020)$ "Discrete optimization algorithm for optimal design of a solar/wind/battery hybrid energy conversion scheme", International Journal of Low-Carbon Technologies, pp.15 https://doi.org/ 10.1093/ijlct/ctaa0671.

9. Katiraei F, Mather B, Momeni A, Li Y, Sanchez G (2015) "Field Verification and Data Analysis of High PV Penetration Impacts on Distribution Systems." IEEE 42nd Photovoltaic Specialist Conference (PVSC), pp. 1-5, https://doi.org/10.1109/PVSC.2015.7356255.

10. Arrilucea $E$, Kuittine $H$ (2018) "US SunShot Initiative and reflections of the Chinese solar energy policies" pp. 1-41, ISBN 978-92-7980161-7 https://doi.org/10.2777/967418.

11. Chathurangi $D$, Jayatunga $U$, Rathnayake $M$, Wickramasinghe $A$, Agalgaonkar A, Perera S (2018) "Potential Power Quality Impacts on LV Distribution Networks with High Penetration Levels of Solar PV." 18th International Conference on Harmonics and Quality of Power, pp. 1-6, https://doi.org/10.1109/ICHQP.2018.8378890.

12. Wong PKC, Kalam A, Barr R (2017) Modelling and analysis of practical options to improve the hosting capacity of low voltage networks for embedded photovoltaic generation. IET Renew Power Gener 11(5):625-632. https://doi.org/10.1049/iet-rpg.2016.0770

13. Maniatopoulos $M$, Lagos D, Kotsampopoulos $P$, Hatziargyriou $N$ (2017) Combined control and power hardware in-the-loop simulation for testing smart grid control algorithms. IET Gener Transm Distrib 11(12):3009-3018. https://doi.org/10.1049/iet-gtd.2016. 1341

14. Kotsampopoulos $P$, Lagos $D$, Hatziargyriou N, Faruque MO, Lauss G, Nzimako O, Forsyth P, Steurer M, Ponci F, Monti A, Dinavahi V (2018) A Benchmark system for hardware-in-the-loop testing of distributed energy resources. IEEE Power Energy Technol Syst J 5(3):94-103

15. Amelang S (2016) “The reform of the Renewable Energy Act: Germany's Energy Transition Revamp Stirs Controversy Over Speed Participation... Clean Energy Wire (CLEW), Berlin, Germany, https:// www.cleanenergywire.org (Accessed in May 2020).

16. Katsanevakis M, Stewart RA, Lu J (2017) Energy storage system utilisation to increase photovoltaic penetration in low voltage distribution feeders. J Energy Storage 1(14):329-347. https://doi. org/10.1016/j.est.2017.07.022

17. Kolhe M, Rasul MJMA (2020) 3-Phase grid-connected building integrated photovoltaic system with reactive power control capability. Renew Energy 154:1065-1075. https://doi.org/10.1016/j. renene.2020.03.075

18. Rasul MJMA, Kolhe M (2019) "Reactive Power Control of a 3-phase Grid-Connected Building Integrated Photovoltaic System", IOP Conference Series: Materials Science and Engineering, (Vol. 605), pp. 1-17. 5th International Symposium on Hydrogen Energy, Renewable Energy and Materials https://doi.org/10.1088/1757899X/605/1/012012

19. Sharma A, Kolhe M, Nils U, Muddineni K, Mudgal A, Garud S (2018) "Voltage Rise Issues and Mitigation Techniques Due to High PV Penetration into the Distribution Network." IEEE International Conference on Automation and Computational Engineering, pp. 72-78 https://doi.org/10.1109/ICACE.2018.8687041.

20. Kotsampopoulos P, Hatziargyriou N, Bletterie B, Lauss G (2013) "Review, analysis and recommendations on recent guidelines for the provision of ancillary services by Distributed Generation." IEEE International Workshop on Inteligent Energy Systems, Austria, pp. 185-190, https://doi.org/10.1109/IWIES.2013.6698583.

21. He W, Yu M, Yu J (2019) Distributed finite-time active power sharing control with generation costs considered. SN Appl Sci 1(12):10. https://doi.org/10.1007/s42452-019-1745-0

22. Saïd-Romdhane MB, Skander-Mustapha S, Slama-Belkhodja I (2020) Analysis of performance criteria for an optimal PV system configuration. SN Appl Sci 2(8):1-8 
23. Benchmark Systems for Network Integration of Renewable and Distributed Energy Resources (2014), ISBN: 978-285-873-270-8.

24. Technical Manual of DIgSILENT Power System Solutions (2020), https://www.digsilent.de" Accessed on 20 May 2020.
Publisher's Note Springer Nature remains neutral with regard to jurisdictional claims in published maps and institutional affiliations. 